\title{
The extended gateway concept in port hinterland container logistics. A theoretical network programming formulation
}

\author{
Fedele Iannone \\ Department of Economics and Quantitative Methods (DIEM), \\ University of Genoa, ITALY \\ E-mail: f.iannone@email.it
}

\begin{abstract}
This paper presents a theoretical network programming formulation of the extended gateway concept in port hinterland container logistics. The model represents a novel extension of the inward interport model developed by Iannone and Thore (2010), as it simultaneously incorporates economic, environmental and social parameters into a single objective framework. A methodological overview on the relations between primal and dual models in linear programming is firstly provided. Based on the configuration of a hypothetical port hinterland network over which typical container distribution operations are performed, a detailed analytical formulation of the primal and dual programs of the interport model is then presented. Possible research developments aimed at applying and improving the model are finally introduced.
\end{abstract}

Key words: port hinterland container logistics, interports, customs, linear programming

JEL codes: C61, C63, D62, L51, L52, L92, L98, R41, R48

\section{Introduction}

\subsection{Port hinterland container logistics}

Port hinterland container logistics is the process of planning, organizing and controlling the multimodal flows of maritime containers and their related information between gateway seaports and inland locations. It also includes the planning, design, implementation and organization of public and private infrastructure, as well as regulatory issues affecting the competitiveness and sustainability of distribution operations.

The hinterland distribution of maritime containers from and to seaports has received a great deal of attention lately due to issues concerning the continuous growth of international trade, the introduction of new ships into the main trade lanes, and the possibility to raise the competitiveness of seaports and supply chains by means of the practical implementation of innovative concepts in inland intermodal logistics systems. Increasing traffic volumes and the introduction of bigger container vessels put pressure on maritime container terminals and inland transport infrastructure, leading to congestion. Accordingly, innovative solutions both for rapid container release operations in seaports and for efficient landside intermodal forwarding of loading units are needed. In this respect, the development of inland multimodal interchange logistics nodes based on the so called 'extended gateway concept' is a relevant option to improve the accessibility and connectivity of seaports and hinterland container networks, while also promoting logistic integration between different types of firms. By this way it is possible to enhance the cost and service efficiency of 
production-distribution and logistic supply chains, stimulating sustainable development and regional economic growth.

\subsection{Interports and the extended gateway concept}

The intermodal nodes in the hinterland network of seaports are described differently in different countries, such as for example 'inland ports' or 'inland terminals' in the United States and Canada, 'strategic rail freight interchanges' in the United Kingdom, 'dry ports' in Sweden and other European countries, and 'interports' in Italy as an abbreviation of 'interior ports' (Cullinane and Wilmsmeier, 2011; Harrison, 2007; Hayuth, 1980; Iannone et al., 2007; Iannone and Thore, 2010; Jaržemskis and Vasiliauskas, 2007; Kirkland, 2007; Leitner and Harrison, 2001; Leveque and Roso, 2002; Rodrigue and Notteboom, 2009; Rodrigue et al., 2010; Roso, 2008; Roso and Lumsden, 2010; Thore, 2007; UNCTAD, 1982, 1991). In some cases, these facilities all have the same functions: multimodal interchange, temporary storage and distribution of intermodal loading units, customs clearance and inspection services, semi-manufacturing and other value added supply chain logistics services, and even wholesale and retail trade. Within the container logistics industry, dry ports have become an increasingly popular means for boosting seaport capacity, facilitating intermodal transport and expanding port hinterlands.

The customs dimension is particularly relevant to discriminate among dry port facilities by qualifying the so called 'extended gateways'. The extended gateway concept exists already for years to indicate a particular type of 'trade facilitation' providing the possibility to rely on a regime of customs continuity between seaports and dry ports. Under extended gateway systems, customs authorities qualify dry ports as an integral part (that is an extension) of specific seaports. The containers can be transported between the seaports and dry ports without the need for customs transit documentation.

Many dry ports effectively operate as an extension of gateway seaports, facilitating the operations of increasingly integrated sea-land intermodal network systems. The organization of port hinterland transport is done by shipping lines and/or maritime terminal companies, respectively in cases of carrier haulage and terminal operator haulage. This saves a great deal of time and costs for the release operations in seaports and is the basis for sustainable transport. Merchants can delay the compliance of all customs formalities, while obtaining the release of their containerized cargoes more closely to their customer base and possibly at a more precisely defined time; maritime terminal companies face less pressure on their facilities thanks to shorter port dwell times ${ }^{1}$; inland intermodal connections can be better planned and utilized; governments can increase their revenue from taxes due to the positive link between trade facilitations and freight flows.

Dry ports acting as extended gateways represent a significant innovation changing the lay-out, flows and scope of inland logistics networks. The extended gateway concept puts great emphasis on the coordination and control of multimodal hinterland flows (Veenstra and Zuidwijk, 2010). Therefore, there are a number of challenges behind dry port development according to the extended gateway perspective: new partnerships have to be established, new business models have to been developed, and transparency of goods and information flows has to be achieved.

\subsection{The need for more comprehensive modelling}

A multitude of quantitative models have been developed to analyze optimal choices in multimodal logistics networks. Bontekoning et al. (2004), Caris et al. (2008), Crainic and Kim (2007), Macharis and Bontekoning (2004), and Schwarz (2008) have reviewed the application of operations research

\footnotetext{
${ }^{1}$ Dwell time is the length of time a container remains at a terminal before being loaded onto a transportation vehicle (ship, train, truck, and barge) for further distribution. It is a critical factor correlated to terminal capacity, and it is affected by: i) customs and other administrative control procedures; ii) the terminal operator's service level; iii) the shipper's supply chain management strategies based on the employment of the terminals as places for the low-cost warehousing of goods.
} 
models and methods in the field of intermodal logistics. Danielis (2006) has put into evidence the role of the economic analysis for investigating intermodal railway transport. Yet, research on the modelling of dry ports is only at the beginning and many issues still need to be more comprehensively considered. Indeed, new types of models need to be developed to address the extended gateway role of dry ports in both supply chain management and port hinterland intermodal infrastructure and service networks. In addition, these models should be formulated based on the socalled 'triple bottom line' or 'sustainable' perspective, by simultaneously incorporating economic, environmental and social performance measures of port hinterland container logistics.

Motivated by these reasons, in this paper a capacitated network programming model featuring linear parameters and constraints - called the 'interport model' - is theoretically illustrated in detail as a tool for the economic analysis and strategic planning of port hinterland container logistics systems according to the extended gateway concept. The model optimizes the inland multimodal distribution of full and empty containers imported through a regional seaport cluster (inward interport model). The loading units can also transit through one or more regional dry port facilities acting as extended gateways (the so-called interports), as well as through extra-regional inland locations featuring a railway terminal, before reaching their final destinations. As presented here, the model is a novel extension of the homonym transhipment model formulated and empirically applied by Iannone and Thore (2010) to investigate the inland distribution of containers imported in Italy through the Campanian sea-land logistics system. Based on a perspective of sustainable logistics, the primal objective function now also internalizes the external costs in terms of greenhouse gas emissions, air pollution, noise, accidents and congestion deriving from inland transport operations.

The major novelty of this analytical tool consists of the detailed modelling of the container release operations at seaports and interports, including the possibility for shippers to postpone storage and customs operations to the interports. More specifically, the interport model allows the measurement of the economic, environmental and social benefits arising from the employment of extended gateways and intermodal transport in port hinterland container distribution. It can simulate long term alternative scenarios in terms of supply of infrastructure and services, demand characteristics, and government and industrial policies. In this respect, the model also enables an examination of possible public and private policy initiatives to stimulate port hinterland intermodal logistics.

\subsection{Plan for this research}

The rest of the chapter is organized as follows. The next section contains an overview of introductory topics in linear programming which includes a conceptual explanation of the relations between primal and dual programs. Section 3 proposes a stylized representation of how a typical port hinterland network over which container distribution operations are performed is entered into the interport model. Based on such hypothetical network, a detailed analytical formulation of the primal and dual programs of the inward interport problem incorporating transport external costs is presented. Finally, an explanation on how to represent simultaneously the primal and dual problems by means of data-boxes is provided. Section 4 introduces possible empirical applications of the model to address practical port hinterland container logistics problems in Northern Europe and Italy. In addition, some limits of the current formulation of the model are highlighted, envisaging further research developments.

\section{Linear programming: a methodological overview}

Linear programming is a method of applied mathematical economic analysis for allocating and utilizing scarce resources in the best possible (optimal) way. A scarce resource is a resource which is available in limited quantities and can also be an output that must be supplied to customers. In linear programs such limitations are stated as constraints.

Linear programming problems can be formulated in either minimizing or maximizing form. The mathematical function to be optimized subjected to constraints is called the 'objective function' and 
can represent, for instance, a cost minimization or profit maximization behaviour. In either case, the originally formulated problem is called the 'primal program'. For every primal program there is a related unique 'dual program' which involves the same data, provides useful information for sensitivity analyses, enhances the understanding of the original model, and allows increased insights into the interpretation of problem solution.

Duality is an extremely important concept in mathematical programming. Whenever one solves a linear programming model, he or she implicitly solves two problems: the primal resource allocation problem, and the dual resource valuation or pricing problem. The main relationships existing between a primal model and its dual can be summarized as follows (see, for instance, Jensen and Bard, 2003, and Thompson and Thore, 1992):

- If the primal problem has a minimizing objective then the dual problem has a maximizing objective and vice versa.

- When the primal model has $n$ variables and $m$ constraints, the dual model has $m$ variables and $n$ constraints.

- For every primal constraint, there is a dual variable. The coefficients of dual variables in dual objective function are the right hand side of the corresponding primal constraints.

- For every primal variable, there is a dual constraint. The right hand sides of dual constraints are the coefficients of the corresponding primal variables in primal objective function.

- The constraint coefficient matrix of the dual is the transpose of the constraint coefficient matrix of the primal.

- All variables in the primal problem are restricted to be nonnegative. As for the dual problem, the sign of the dual variable corresponding to a right way primal constraint is nonnegative whereas the sign of the dual variable of a wrong way primal constraint is nonpositive; the dual variable of an equality primal constraint is unconstrained ${ }^{2}$.

- The dual of a dual is the primal problem.

In addition, a primal problem and its dual also share relationships in their solution, and it is always possible to obtain primal solution from dual solution and vice versa.

The linear formulation of a programming model provides an evaluation of the scarcity of resources by means of 'shadow prices' or 'dual variables'. Each constraint in the primal problem has an associated shadow price which can be interpreted as the marginal value of the resources represented by the coefficient in the right hand side of the constraint. It is the amount by which the optimal value of the primal objective function would change per allowable unit variation in the right hand side of the corresponding constraint, all other parameters held as constant. To sum up, shadow prices or dual variables indicate how much one would be willing to pay for additional units of given limited resources, thus representing the marginal utility of relaxing the corresponding primal constraints or equivalently the marginal cost of strengthening the constraints.

Apart from the constraints, also all variables of a primal programming problem have what is known as a marginal or imputed value. This value is called the 'reduced cost' for each variable. The variables included in the optimal solution of a problem automatically have a reduced cost of zero. Instead, the reduced cost for any variable not included into the final solution can be interpreted as the penalty one would pay to force the variable into the solution. In a minimizing model, the optimal solution would increase by the amount of the penalty. In a maximizing problem, the solution would decrease. In general, if a primal variable is non-basic, the value of its reduced cost coefficient is the value of the slack/surplus variable ${ }^{3}$ of the corresponding dual constraint. If a dual

\footnotetext{
${ }^{2}$ When the objective function of a linear program is minimizing, greater or equal to inequalities $(\geq)$ are "right way inequalities" and less than or equal to $(\leq)$ inequalities are "wrong way inequalities". For a maximizing objective, $\leq$ are right way inequalities and $\geq$ are wrong way inequalities (Thompson and Thore, 1992; Thore and Iannone, 2005). ${ }^{3}$ Slack and surplus variables respectively convert $\leq$ and $\geq$ inequalities to equalities. These quantities are zero for those constraints that are satisfied exactly.
} 
variable is non-basic, the value of its reduced cost coefficient is the value of the slack/surplus variable of the corresponding primal constraint.

The primal and dual programs of a linear programming model are tied together according to the so called 'complementary slackness conditions'. In particular, complementary slackness is the relationship between slack and/or surplus variables in the primal problem and the opportunity costs in the dual. For instance, if a primal resource has positive slack, it is not binding on the optimal solution. Making more of this resource available will not improve the optimal value of the objective function. At the same time, because all of the resource is not being used, it has a dual price of zero. If one uses more of it, he or she does not sacrifice any utility from another use. If, on the other hand, the resource has zero slack, it is called a 'binding constraint'. All of the resource is being used, and making more of it available will improve the optimal value of the objective function. However, it will have a positive opportunity cost because the additional units will have to be taken from some other use.

Compared with other programming model types, linear models are by far the easiest to solve. Optimal values of primal and dual variables, including reduced costs, are given by modern computer programs as part of the optimal solution. Large-scale computer codes are widely available for most mainframes and workstations as well as for microcomputers, with only limited restrictions.

\section{The interport model: a stylized formulation}

The interport model is an inventory theoretic and capacitated linear programming model optimizing the road and rail distribution of full and empty containers over an inland network encompassing seaports, interports and other locations.

This section presents a stylized formulation of the primal and dual programs of the inward interport model incorporating transport external costs. Such example covers all the features of real life port hinterland container network problems that can be investigated by means of empirical applications of the model.

\subsection{Stylized port hinterland container distribution network and problem description}

Figure 1 firstly illustrates a hypothetical first tier regional node infrastructure system for container traffic. This system comprises a single seaport represented by node 1 , and a single interport featuring the two 'virtual nodes' 2 and 3 that are supposed to have an identical geographical location but involve in part different interport processing activities. Finally, there are three other regional and extra-regional inland locations, that are the nodes $4,5,6$, of which only 4 and 5 have a railway terminal.

The seaport node 1 is the origin node of this small network, while nodes $2,4,5$ and 6 are the destination nodes. There is one influx into the network: the supply of imported containers at node 1 . There are four effluxes: the demands at nodes 2, 4, 5 and 6 for containers discharged at the seaport. Nodes 2, 4 and 5 are also intermediate nodes enabling the multimodal transhipment of containers transported from the seaport to destination. Node 3 is a pure intermediate multimodal transhipment node because it does not feature a container demand; it is supposed to also perform a customs function and it is connected to the seaport by railway only for container transfers under the responsibility of shipping lines (carrier haulage) and without any accompanying inland customs transit document ${ }^{4}$. In general, node 3 is employed only for the handling of full containers. Both virtual nodes 2 and 3 have the same outbound multimodal connections.

\footnotetext{
${ }^{4}$ In compliance with the customs regulations currently in force in Italy, only the railway transport permits the necessary conditions of fiscal safety related to the inland haulage without any accompanying inland transit document for containerized cargoes that have not been nationalized yet through customs clearance. Of course, the hypothetical network shown in Figure 1 can be easily expanded to take also account of other inland logistics solutions such as those based on inland waterway transport, as well as those arranged under the customs license of maritime terminal companies.
} 


\section{LEGEND}
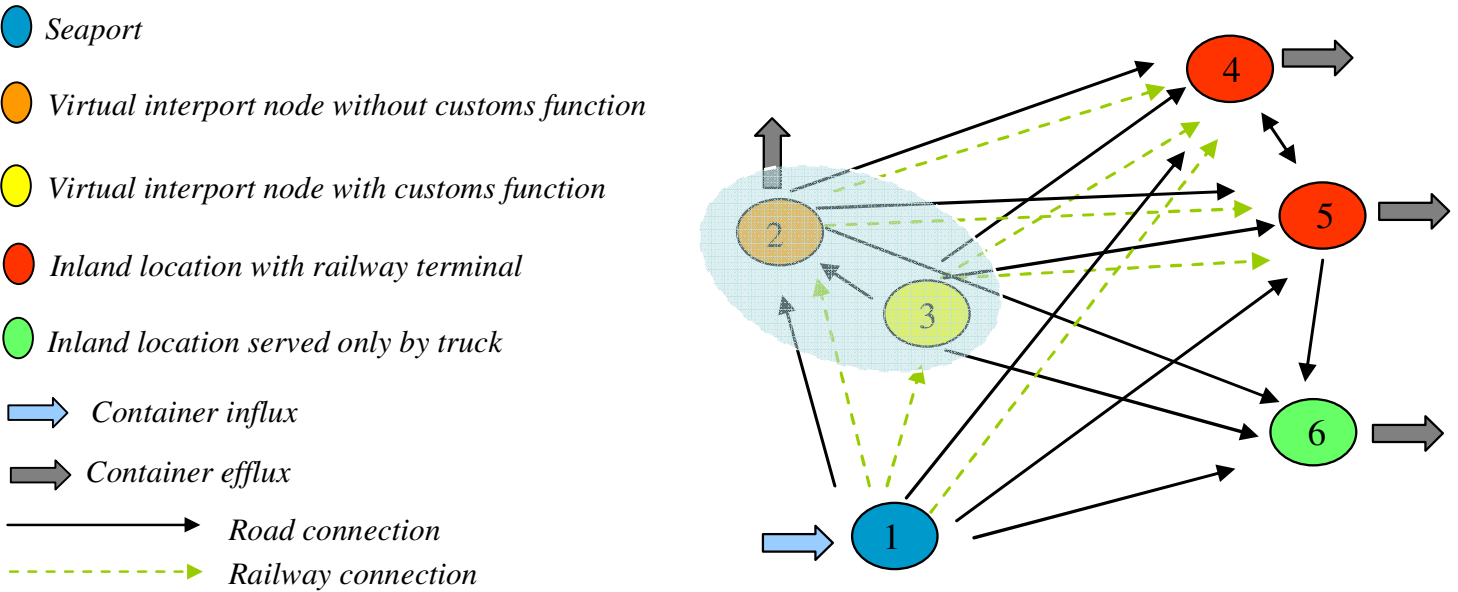

Figure 1 Stylized multimodal port hinterland logistics network with virtual interport nodes

As for the railway links represented in Figure 1, the seaport node 1 is connected to the node 4 and to the nodes 2 and 3 . Node 3 is reachable from the seaport node by railway carrier haulage only and exclusively for the forwarding of customs bonded full containers. Nodes 2 and 3 are also linked to the nodes 4 and 5 .

Each railway service available in real life at the interport is represented by the corresponding specific rail connections simultaneously available at each virtual interport node. In particular, the rail service from the seaport to the interport is supposed to simultaneously carry containers from node 1 to node 2 and from node 1 to node 3 . In the same way, the rail service from the interport to the node 4 simultaneously carries containers from node 2 to node 4 and from node 3 to node 4 . And so on.

As for the road links, node 1 is connected to all the other nodes of the network, excluding the virtual node 3 . Both virtual nodes 2 and 3 are linked by road to all the other inland locations of the network; furthermore, road transport at a zero generalized cost is admitted from virtual node 3 to virtual node 2 to meet the container demand of importing operators located in the interport. Finally, the other inland nodes having a railway terminal are connected by truck to some inland locations that are directly linked with the regional seaport-interport system. In particular, node 4 can also be employed as intermediate node to serve node 5 , while node 5 can also be employed as intermediate node to serve nodes 4 and 6 .

In practice, at the inland nodes served by railway it is assumed the possibility to perform multimodal transhipment operations for various O/D combinations, that is for traffic relations from the supplying seaport to the inland final demanding nodes. More specifically, at the extra-regional nodes served by railway it is assumed the possibility to perform only rail-to-truck and truck-to-truck transhipment operations, while at the interport it is also assumed the possibility of railway-torailway and truck-to-railway transhipment operations.

The stylized network in Figure 1 is assumed to be typified by relatively small inland locations featuring a railway terminal (including the interport location). Similarly to the other nodes of the network, also the inland locations served by railway are assumed as centroid areas in which the traffic of demanded containers terminates. Given this configuration of the network, intra-zonal post haulage activities at these locations are assumed to serve negligible (very short) distances. Hence, at the moment, such activities are omitted from the modelling entirely.

To sum up, once an imported full container has been cleared by customs at node 1 , it can be directly sent to one of the demand locations 2, 4,5 and 6. Alternatively, it can be sent to destination by transiting through one or more intermediate transhipment nodes (excluding the virtual interport node 3 with customs function). A similar forwarding scheme applies to empty containers. 
But there is also another possibility for the distribution of full containers. Rather than being cleared by customs at node 1 , a full container may be shipped by bonded and sealed rail transportation from node 1 to node 3 , which virtually represents the customs clearing facility located at the interport in the hinterland. Once cleared here, the container may be transferred to its final demand location. Of course, empty containers do not require customs clearance before being released from intermodal nodes.

The splitting of a single interport facility into two separate virtual nodes enables the formulation of a standard linear programming model for the entire network, thus avoiding explicit $0-1$ programming features to handle the decisions of where to carry out the customs clearance and storage operations for full containers.

\subsection{The primal programming model}

As presented here, the primal program of the interport model minimizes the total social generalized logistic cost for port hinterland multimodal distribution of imported full and empty containers (inward interport model), subjected to flow balance constraints at all nodes, nonnegativity constraints on endogenous variables, and capacity constraints on all rail connections. The model also features a road supply sub-model for the quantification of road transport times at national scale according to the Road Code regulations.

The interport model solves for the optimal inland routing of maritime containers discharged at one or more seaports. This task includes finding the detailed quantities of standardized loading units to be shipped from seaports, the transportation modal choice along each inland link, and the detailed pathway through the system chosen, including the possibility of multimodal transhipment operations at one or more regional interports and at other intermediate inland nodes featuring a railway terminal.

The model also determines whether shippers will choose to have their containerized consignments controlled and cleared by customs directly at the seaports, or whether they will prefer to comply with customs formalities at the interports. By means of parameters representing dwell times, free of charge storage times, handling charges, demurrage charges, probabilities and costs of customs controls, the interport model simulates in detail the container release operations and their associated pricing mechanisms at seaport and interport terminals ${ }^{5}$, including the possibility of relocating storage and customs operations from the seaports to the interports (i.e. the extended gateway concept). In this respect, the model allows for spelling out various arrangements of customs checks on full containers (automated computerized controls, documentary control, X-ray scanning controls, and physical inspections).

The primal equilibrium solution of the model can be broken down into merchant flows and carrier flows, representing in any case the optimum of a hypothetical shipper operating the entire network. In the common fashion, the overall solution for this economic agent can be shown to coincide with the decentralized solutions of individual programs for each participating logistic agent who ships containers through the network.

All model's elements are for one planning period (which in the empirical applications has corresponded to an operational year), and are assumed not to vary during the planning horizon. The notations used in the model are shown below.

\footnotetext{
${ }^{5}$ Terminal operators offer container storage services to decouple the successive steps in the transport chain and they normally provide a limited amount of free of charge storage time which should allow for the customers to arrange customs formalities and other authorities to do their required clearances. Storage rates after free time (demurrage charges) are charged by terminal companies to optimize the yard productivity, minimizing the container dwell time depending on deliberate supply chain management strategies of using terminals as low cost warehouses. Also customs and administrative procedures may add substantially to the dwell time, and therefore to the direct and indirect costs for shippers. In some cases, shippers endeavour to have all necessary containers checked within free storage time provided by terminal companies, with this typically being not achieved for 100 per cent of container volumes and determining significant generalized costs to be borne.
} 


\section{Indices:}

$I$ : set of all nodes of the network $=\{1,2,3,4,5,6\}$

$L(I)$ : set of all intermodal nodes of the regional logistics system $=\{1,2,3\}$

$N(L)$ : set of intermodal nodes of the regional logistics system excluding virtual interport nodes with customs function $=\{1,2\}$

$O(L)$ : set of intermodal nodes of the regional logistics system excluding virtual interport nodes without customs function $=\{1,3\}$

$P(O)$ : set of seaport nodes of the regional logistics system $=\{l\}$

$Q(N)$ : set of virtual interport nodes without customs function $=\{2\}$

$D(O)$ : set of virtual interport nodes with customs function $=\{3\}$

$Z(I)$ : set of all inland locations demanding containers $=\{2,4,5,6\}$

$E(Z)$ : set of inland locations (excluding interports) demanding containers $=\{4,5,6\}$

$R(Z)$ : set of inland locations without rail terminal and demanding containers $=\{6\}$

$H(I)$ : set of inland locations performing an intermediate multimodal transhipment function:

$\{2,3,4,5\}$

$T$ : set of container types $=\{$ full, empty $\}$

$M$ : set of admitted inland transportation modes $=\{$ rail, truck $\}$

Road_Type: set of road linear infrastructure types $=\{$ motorway, other roads $\}$

$A:$ set of one-way railway services $=\left\{1 \_(2+3), 1 \_4,(2+3) \_4,(2+3) \_5\right\}$

Customs: set of all customs control types $=\{A C, D C, P I, S C\}^{6}$

Customs2 (Customs): set of customs control types which do not entail additional direct customs costs $=\{A C, D C\}$

Customs3 (Customs): set of customs control types entailing additional direct customs costs $=$ $\{P I, S C\}$

\section{Parameters:}

$\left[\right.$ Demand $\left._{p i}^{t}\right]$ : vector of demands specified in number of containers of type $t \in T$ (measured in TEU) by origin-destination pair (that is from each seaport node $p \in P$ towards each node $i \in I$ )

$\left[\right.$ Road_dist $\left.t_{i j}^{\text {road_type }}\right]$ : vector of kilometer lengths of road linear infrastructure

road_type $\in$ Road_type between nodes $i \in I$ and $j \in I$

$\left[\right.$ Tot_road_dist $\left.t_{i j}\right]$ : vector of kilometer lengths of total road linear infrastructure between nodes $i \in I$ and $j \in I$, that are given as Tot_road_dist $t_{i j}=\sum_{\text {road_type } \in \text { Road_Type }}$ Road_dist $_{i j}^{\text {road_type }}$

$\left[\right.$ Road_speed $\left.^{\text {road_type }}\right]$ : vector of admitted average speeds (expressed in $\mathrm{km} / \mathrm{h}$ ) of transport by truck over road linear infrastructure road_type $\in$ Road_type

\footnotetext{
${ }^{6}$ AC stands for Automated Computerized Control, DC for Documentary Control, PI for Physical Inspection, and SC for X-ray Scanning.
} 
$\left[\right.$ Road_driv_time $\left.e_{i j}\right]$ : vector of admitted driving times (expressed in number of hours) for transport by truck between nodes $i \in I$ and $j \in I$, that are calculated as

$R o a d_{-} d r i v_{-}$time $_{i j}=\left(\frac{\text { Road_dist }_{i j}^{\text {motorway } \in \text { Road_Type }}}{\text { Road_speed }^{\text {motorway } \in \text { Road_Type }}}\right)+\left(\frac{\text { Road_dist }_{i j}^{\text {other roads } \in \text { Road_Type }}}{\text { Road_speed }^{\text {other roads } \in \text { Road_Type }}}\right)$

$\left[\right.$ Rests_time $\left._{i j}\right]$ : vector of times for rests (expressed in number of hours) prescribed by Road regulations for transport by truck between nodes $i \in I$ and $j \in I$

$\left[\right.$ Stops_time $\left._{i j}\right]$ : vector of times for stops (expressed in number of hours) prescribed by Road regulations for transport by truck between nodes $i \in I$ and $j \in I$

$\left[\right.$ Rail $_{-}$dist $\left._{i j}\right]$ : vector of kilometer lengths of rail linear infrastructure between nodes $i \in I$ and $j \in I$

$\left[\right.$ Rail_time $\left.e_{i j}^{t}\right]$ : vector of times for railway transport of containers of type $t \in T$ between nodes

$i \in I$ and $j \in I$, where Rail_time $e_{i j}^{f u l l \in T}$ is given, while Rail_time $e_{i j}^{e m p t y \in T}=R a i l \_t i m e_{i j}^{f u l l \in T}$ for all $i, j \neq d \in D \subseteq I$, and Rail_time $e_{i \in I, d \in D}^{\text {empty } \in T}=$ Rail_time $_{d \in D, i \in I}^{\text {empty } \in T}=0$ (virtual interport nodes $d \in D$ can only receive and forward full containers)

$\left[\right.$ Tot_transport_time $\left.e_{i j}^{t m}\right]$ : vector of total travel times (expressed in number of hours) for transport of containers of type $t \in T$ by mode $m \in M$ between nodes $i \in I$ and $j \in I$, where

Tot_transport_time $e_{i j}^{t, r a i l \in M}=R a i l_{-} t i m e_{i j}^{t}$, and

Tot_transport_time $e_{i j}^{t, t r u c k \in M}=R o a d_{-} d r i v_{-} t i m e_{i j}+$ Rests_time $_{i j}+$ Stops_time $e_{i j}$

$\left[\right.$ Transport $_{-}$fare $\left._{i j}^{t m}\right]$ : vector of unit prices (measured in Euros/TEU) for transport of containers of type $t \in T$ by mode $m \in M$ between nodes $i \in I$ and $j \in I$

$\left[\right.$ Gas_cost $\left.{ }^{t m}\right]$ : vector of external unit costs (in Euros/TEU-km) for emissions of greenhouse gases deriving from transport of containers of type $t \in T$ by mode $m \in M$

$\left[\right.$ Air_cost $\left.t^{t m}\right]$ : vector of external unit costs (in Euros/TEU-km) of air pollution deriving from transport of containers of type $t \in T$ by mode $m \in M$

$\left[\right.$ Noise_cost $\left.{ }^{t m}\right]$ : vector of external unit costs (in Euros/TEU-km) of noise deriving from transport of containers of type $t \in T$ by mode $m \in M$

$\left[\right.$ Accident_cost $\left.{ }^{t m}\right]$ : vector of external unit costs (in Euros/TEU-km) of accidents deriving from transport of containers of type $t \in T$ by mode $m \in M$

$\left[\right.$ Congestion_cost $\left.t^{\text {tm }}\right]$ : vector of external unit costs (in Euros/TEU-km) of congestion deriving from transport of containers of type $t \in T$ by mode $m \in M$

$\left[\right.$ Tot_extern_cost $\left.t_{i j}^{t m}\right]$ : vector of total external unit costs (in Euros/TEU) deriving from transport of containers of type $t \in T$ by mode $m \in M$ between nodes $i \in I$ and $j \in I$, where 


$$
\begin{aligned}
& \text { Tot_extern_cost } t_{i j}^{t, t r u c k \in M}=
\end{aligned}
$$

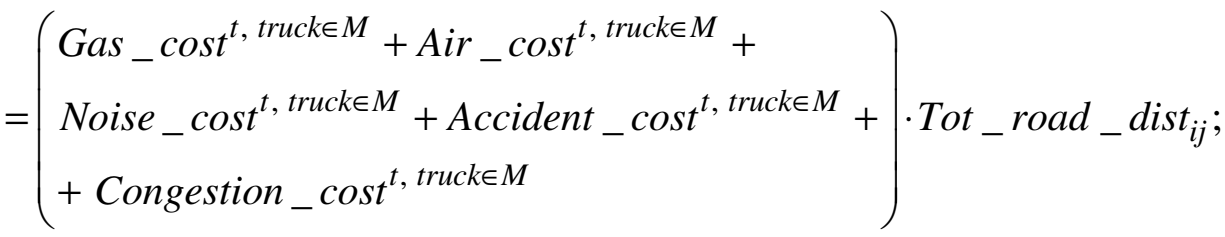

while Tot_extern_cost $t_{i j}^{t, r a i l \in M}=$

$$
=\left(\begin{array}{l}
\text { Gas_cost } t^{t, r a i l \in M}+\text { Air_cost } t^{t, r a i l \in M}+ \\
\text { Noise_cost } t^{t, r a i l \in M}+\text { Accident_cost } t^{t, r a i l \in M}+{ }^{t} \\
+ \text { Congestion_cost } t^{t, r a i l \in M}
\end{array}\right) \cdot \text { Rail_dist }_{i j}
$$

Annual_rate: scalar representing the annual opportunity and economic-technical depreciation cost rate of containerized cargoes

[Import_value]: scalar representing the average unit customs declared value (expressed in

Euros/TEU) of containerized import cargoes disembarked at the regional seaport system

Leas_cost: scalar representing the container leasing unit charge per day (expressed in Euros/TEU/day)

$\left[c_{i j}^{f u l l \in T, m}\right]$ : vector of total social generalized unit costs (in Euros/TEU) for transport of containers of type full $\in T$ by mode $m \in M$ between nodes $i \in I$ and $j \in I$, that are calculated as $c_{i j}^{f u l l \in T, m}=$ Transport_fare $e_{i j}^{\text {full } \in T, m}+$ Tot $_{-}$extern_cost $t_{i j}^{f u l l \in T, m}+$

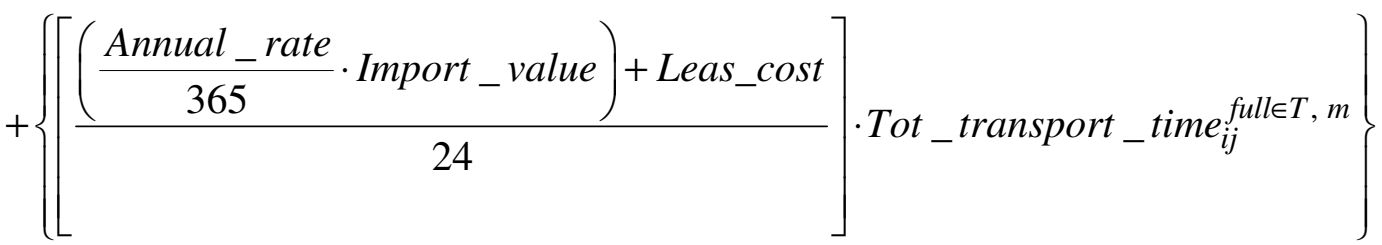

where the first two terms are respectively the direct transport cost and the total transport external cost (in Euros/TEU), while the third term is the time related cost during transport operations (i.e. the sum of in-transit inventory holding cost and container leasing cost, in Euros/TEU) $\left[c_{i j}^{e m p t y \in T, m}\right]$ : vector of total social generalized unit transport costs (in Euros/TEU) for containers of type empty $\in T$ by mode $m \in M$ between nodes $i \in I$ and $j \in I$, that are calculated as

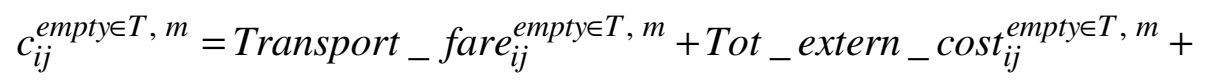
$+\left(\frac{\text { Leas_cost }}{24} \cdot T o t_{-}\right.$transport_time $\left.e_{i j}^{\text {empty } \in T, m}\right)$

where the first two terms are respectively the direct transport cost and the total transport external cost (in Euros/TEU), while the third term is the time related cost during transport operations (i.e. container leasing cost, in Euros/TEU)

$[$ DwTime_empty $]$ : vector of unit dwell times (expressed in number of days/TEU) for empty containers at node $n \in N$ 
$\left[\right.$ DwTime full $_{-}$port ${ }_{p}^{\text {customs, }}$ m $]:$ vector of unit port dwell times (expressed in number of days/TEU) for full containers submitted to customs control type customs $\in$ Customs at seaport node $p \in P$, and leaving the same node by transport mode $m \in M$

$\left[\right.$ DwTime full $_{-}$port $\left.\_C B_{p}\right]$ : vector of unit port dwell times (expressed in number of days/TEU) for full containers to be cleared at the interport and leaving the seaport node $p \in P$ by railway carrier haulage under customs bond (without any accompanying inland customs transit document) $\left[\right.$ DwTime full_interport $\left._{-} A_{q}^{m}\right]$ : vector of unit interport dwell times (expressed in number of days/TEU) for full containers already cleared by customs at the seaport node and leaving the virtual interport node $q \in Q$ by transport mode $m \in M$

$\left[\right.$ DwTime_full_interport $\left.{ }_{d}^{\text {customs }, m}\right]$ : vector of unit interport dwell times (expressed in number of days/TEU) for full containers submitted to customs control type customs $\in$ Customs at virtual interport node $d \in D$, and leaving the same node by transport mode $m \in M$

$\left[\right.$ Ratio $_{-}$port $\left._{p}^{\text {customs }}\right]$ : vector of ratios $(\%)$ of disembarked full containers submitted to customs control type customs $\in$ Customs before to be cleared at seaport node $p \in P$

$\left[\right.$ Ratio_interport $\left.{ }_{d p}^{\text {customs }}\right]$ : vector of ratios $(\%)$ of full containers arriving at virtual interport node $d \in D$ from seaport node $p \in P$ by rail under customs bond (without any accompanying inland customs transit document) and to be submitted to customs control type customs $\in$ Customs , that are given by Ratio_interport ${ }_{d p}^{\text {customs }}=$ Ratio $_{-}$port $_{p}^{\text {customs }}$ for all $d \in D$

$\left[W a_{-}\right.$DwTime_full_port $\left.{ }_{p}^{m}\right]$ : vector of weighted average unit port dwell times (measured in number of days/TEU) of full containers cleared by customs at seaport node $p \in P$ and leaving the same node by transport mode $m \in M$, that are given by

Wa_DwTime $a_{-}$full $_{-}$port $_{p}^{m}=\sum_{\text {customs } \in \text { Customs }}\left(\right.$ DwTime full $_{-}$port $_{p}^{\text {customs, } m} \cdot$ Ratio $\left._{\text {p port }}^{\text {customs }}\right)$

$\left[\right.$ Wa_DwTime_full_interport $\left.{ }_{p d}^{m}\right]$ : vector of weighted average unit interport dwell times

(measured in number of days/TEU) of full containers arriving in virtual interport node $d \in D$ by railway carrier haulage under customs bond from seaport node $p \in P$, cleared by customs at the same node $d \in D$, and leaving by transport mode $m \in M$, that are given by

Wa_DwTime_full_interport ${ }_{p d}^{m}=$

$=\sum_{\text {customs } \in \text { Customs }}\left(\right.$ DwTime $_{-}$full_interport $_{d}^{\text {customs }, m} \cdot$ Ratio_interport $\left._{d p}^{\text {customs }}\right)$

$\left[\right.$ Free $_{-}$time $\left._{l}\right]$ : vector of free of charge container storage unit times (measured in number of days/TEU) at node $l \in L$

$\left[\right.$ DemurrCharge $\left.e_{l}^{t}\right]$ : vector of demurrage unit charges (measured in Euros/TEU) for containers of type $t \in T$ at node $l \in L$

$\left[\right.$ HandlCharge $\left.t_{l}^{t}\right]$ : vector of container handling unit charges (measured in Euros/TEU) for containers of type $t \in T$ at node $l \in L$ 
$\left[\right.$ Additional_customs_charge $\left.e_{o}^{\text {customs } 3}\right]$ : vector of additional customs unit charges (expressed in Euros/TEU) for full containers submitted to customs control type customs $3 \in$ Customs 3 at node $o \in O$

$\left[\right.$ Port_dir_cost $\left.1_{p}^{\text {customs } 2, m}\right]:$ vector of direct unit costs (expressed in Euros/TEU) for handling and storage of full containers submitted to customs control type customs $2 \in$ Customs 2 at seaport node $p \in P$, and leaving the same node by transport mode $m \in M$, that are calculated as

$$
\begin{aligned}
& \text { Port_dir_cost } 1_{p}^{\text {customs } 2, m}=
\end{aligned}
$$

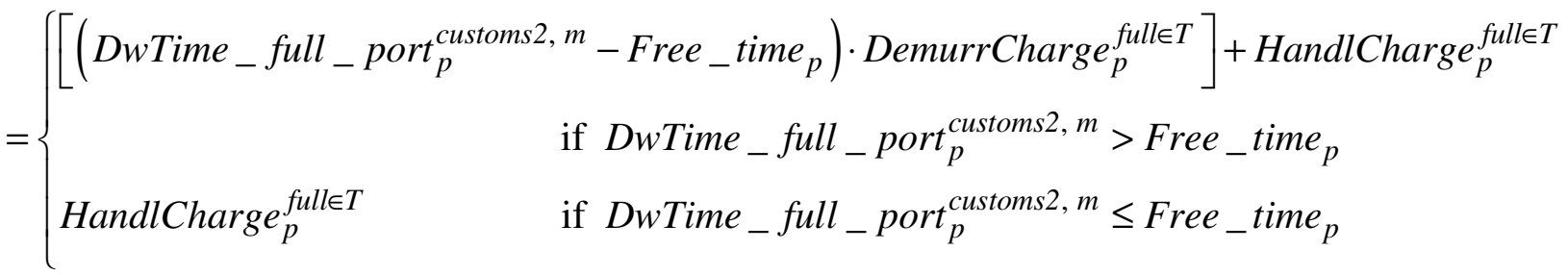

where $\left[\left(\right.\right.$ DwTime $_{-} f u l l_{-}$port ${ }_{p}^{\text {customs } 2, m}-$ Free $_{-}$time $\left._{p}\right) \cdot$ DemurrCharge $\left._{p}^{f u l l \in T}\right]$ is the unit cost of container storage (Euros/TEU), and HandlCharge $e_{p}^{\text {fulleT }}$ is the unit charge for container handling (Euros/TEU).

$\left[\right.$ Port_dir_cost $\left.2_{p}^{\text {customs } 3, m}\right]:$ vector of direct unit costs (expressed in Euros/TEU) for handling, storage, and customs control of full containers submitted to customs control type customs $3 \in$ Customs 3 at seaport node $p \in P$, and leaving the same node by transport mode $m \in M$, that are calculated as

Port_dir_cost $2_{p}^{\text {customs } 3, m}=$

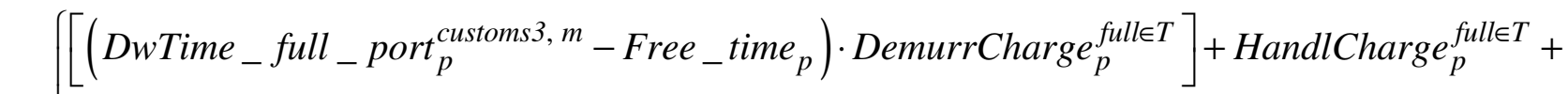

$$
\begin{aligned}
& =\left\{\begin{aligned}
+ \text { Additional_customs } \\
- \\
\text { charge }
\end{aligned}\right. \\
& \text { HandlCharge }_{p}^{\text {full } \in T}+\text { Additional_customs_charge }{ }_{p}^{\text {customs } 3} \\
& \text { if } \text { DwTime }_{-} \text {full_ } \text { port }_{p}^{\text {customs } 3, m} \leq \text { Free }_{-} \text {time }_{p}
\end{aligned}
$$

[Interport_dir_cost $\left.1_{d}^{\text {customs } 2, m}\right]:$ vector of direct unit costs (expressed in Euros/TEU) for

handling and storage of full containers submitted to customs control type customs $2 \in$ Customs 2 at virtual interport node $d \in D$, and leaving the same node by transport mode, that are calculated as Interport_dir_cost $1_{d}^{\text {customs } 2, m}=$

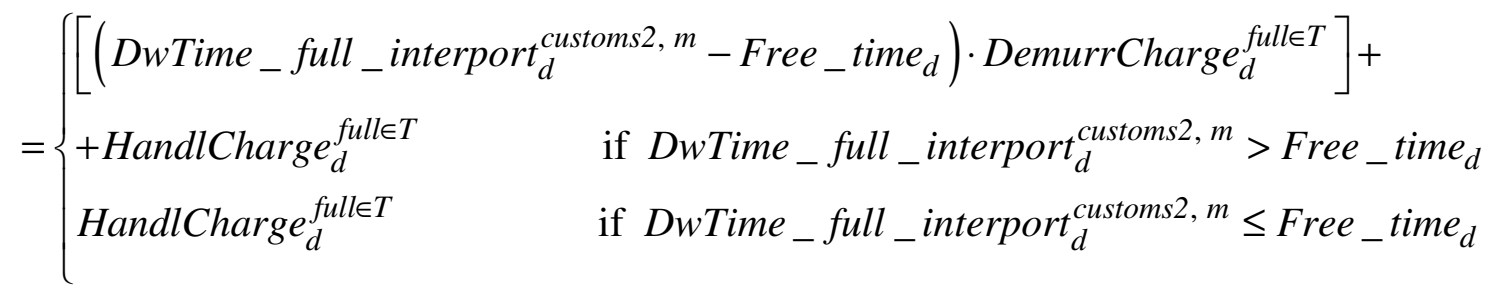


where $\left[\left(\right.\right.$ DwTime $\_$full_interport ${ }_{d}^{\text {customs } 2, m}-$ Free $_{-}$time $\left._{d}\right) \cdot$ DemurrCharge $\left._{d}^{\text {full } \in T}\right]$ is container storage cost, and HandlCharge $e_{d}^{\text {fulleT }}$ is container handling charge [Interport_dir_cost $\left.2_{d}^{\text {customs } 3, m}\right]:$ vector of direct unit costs (expressed in Euros/TEU) for handling storage, and customs control of full containers submitted to customs control type customs $3 \in$ Customs 3 at virtual interport node $d \in D$, and leaving the same node by transport mode $m \in M$, that are calculated as

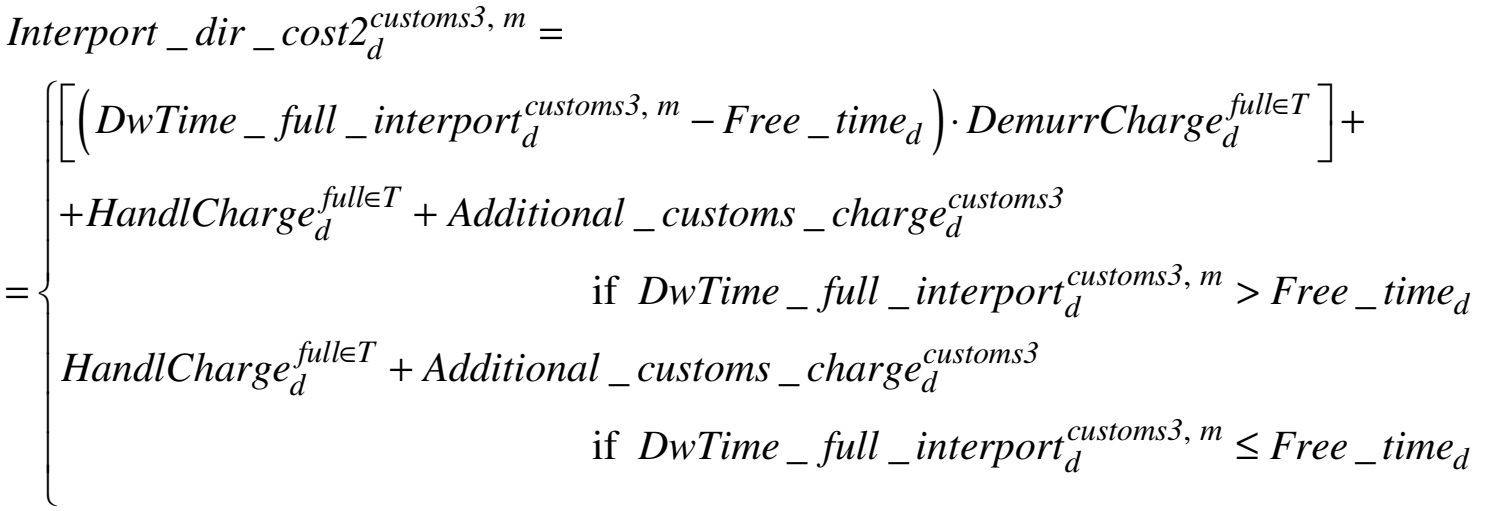

$\left[f_{n}\right]$ : vector of total generalized unit costs (in Euros/TEU) of release operations for empty containers at intermodal node $n \in N$, that are calculated as

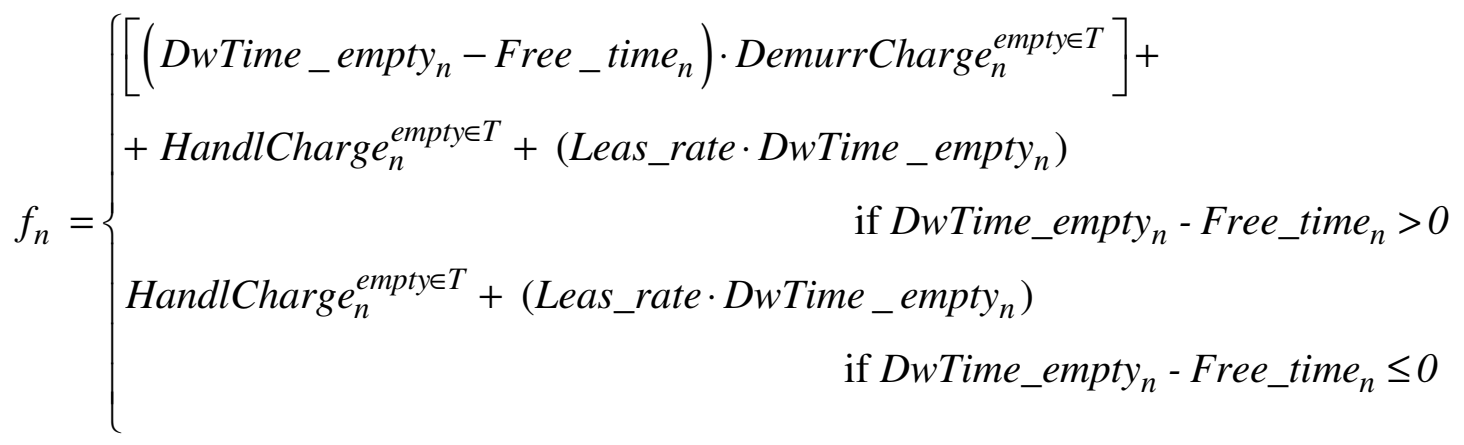

where $\left[\left(\right.\right.$ DwTime_empty $_{n}-$ Free_time $\left._{n}\right) \cdot$ DemurrCharge $\left._{n}^{\text {empty } \in T}\right]+$ HandlCharge $_{n}^{\text {empty } \in T}$ is terminal operation cost, and (Leas_rate $\cdot$ DwTime_empty $\left.{ }_{n}\right)$ is container leasing cost $\left[g_{p}^{m}\right]$ : vector of weighted average total generalized unit port costs (in Euros/TEU) of the release operations for full containers cleared by customs at seaport node $p \in P$ and leaving the same node by transport mode $m \in M$, that are calculated as

$$
\begin{aligned}
& g_{p}^{m}=\left[\left(\frac{\text { Annual_rate }}{365} \cdot \text { Import_value }\right) \cdot \text { Wa_DwTime_full_port }{ }_{p}^{m}\right]+ \\
& +\left(\text { Leas_cost } \cdot W a_{-} \text {DwTime_full_port }{ }_{p}^{m}\right)+ \\
& +\sum_{\text {customs } 2 \in \text { Customs } 2}\left(\text { Port_dir_cost } I_{p}^{\text {customs } 2, m} \cdot \text { Ratio }_{-} \text {port } t_{p}^{\text {customs } 2}\right)+ \\
& +\sum_{\text {customs } 3 \in \text { Customs } 3}\left(\text { Port_dir_cost } 2_{p}^{\text {customs } 3, m} \cdot \text { Ratio }_{-} \text {port } t_{p}^{\text {customs } 3}\right)
\end{aligned}
$$


where $\left[\left(\frac{\text { Annual_rate }}{365} \cdot\right.\right.$ Import_value $) \cdot W a_{-}$DwTime _full_port $\left.{ }_{p}^{m}\right]$ is weighted average intransit inventory holding cost, $\left(\right.$ Leas_cost $\cdot W a_{-}$DwTime full $_{-}$port $\left.{ }_{p}^{m}\right)$ is weighted average container leasing cost, and

$$
\begin{aligned}
& \sum_{\text {customs } 2 \in \text { Customs } 2}\left(\text { Port_dir } \_ \text {cost } 1_{p}^{\text {customs } 2, m} \cdot \text { Ratio }_{-} \text {port }{ }_{p}^{\text {customs } 2}\right)+ \\
& +\sum_{\text {customs } 3 \in \text { Customs } 3}\left(\text { Port }- \text { dir } \_ \text {cost } 2_{p}^{\text {customs } 3, m} \cdot \text { Ratio }_{-} \text {port }{ }_{p}^{\text {customs } 3}\right) \text { is weighted average handling, }
\end{aligned}
$$
storage and customs control cost

$\left[k_{p}\right]$ : vector of total generalized unit port costs (in Euros/TEU) of the release operations for full containers leaving the seaport node $p \in P$ by railway carrier haulage under customs bond (without any accompanying inland customs transit document) towards the virtual interport node with customs function, that are calculated as

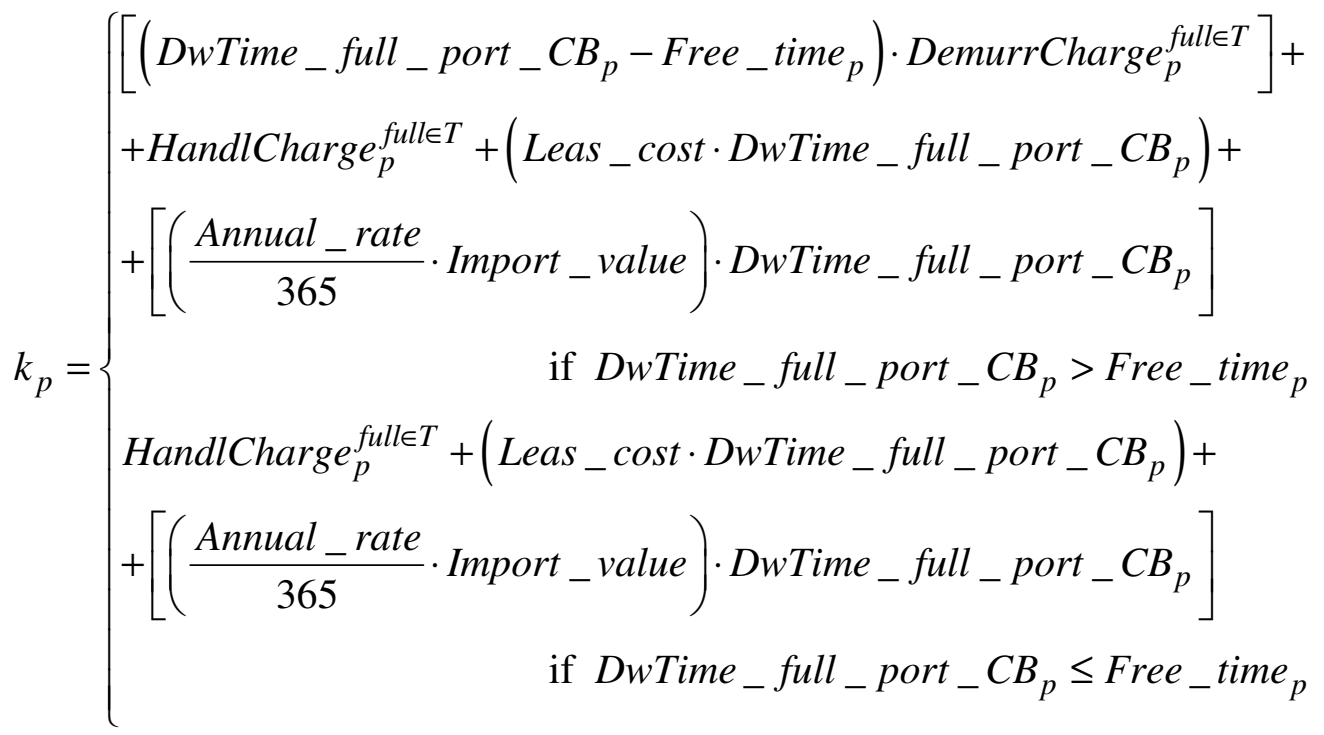

$\left[s_{q}^{m}\right]:$ vector of total generalized unit interport costs (in Euros/TEU) of the release operations for full containers already cleared by customs in the seaport node and leaving the virtual interport node $q \in Q$ by transport mode $m \in M$, that are calculated as

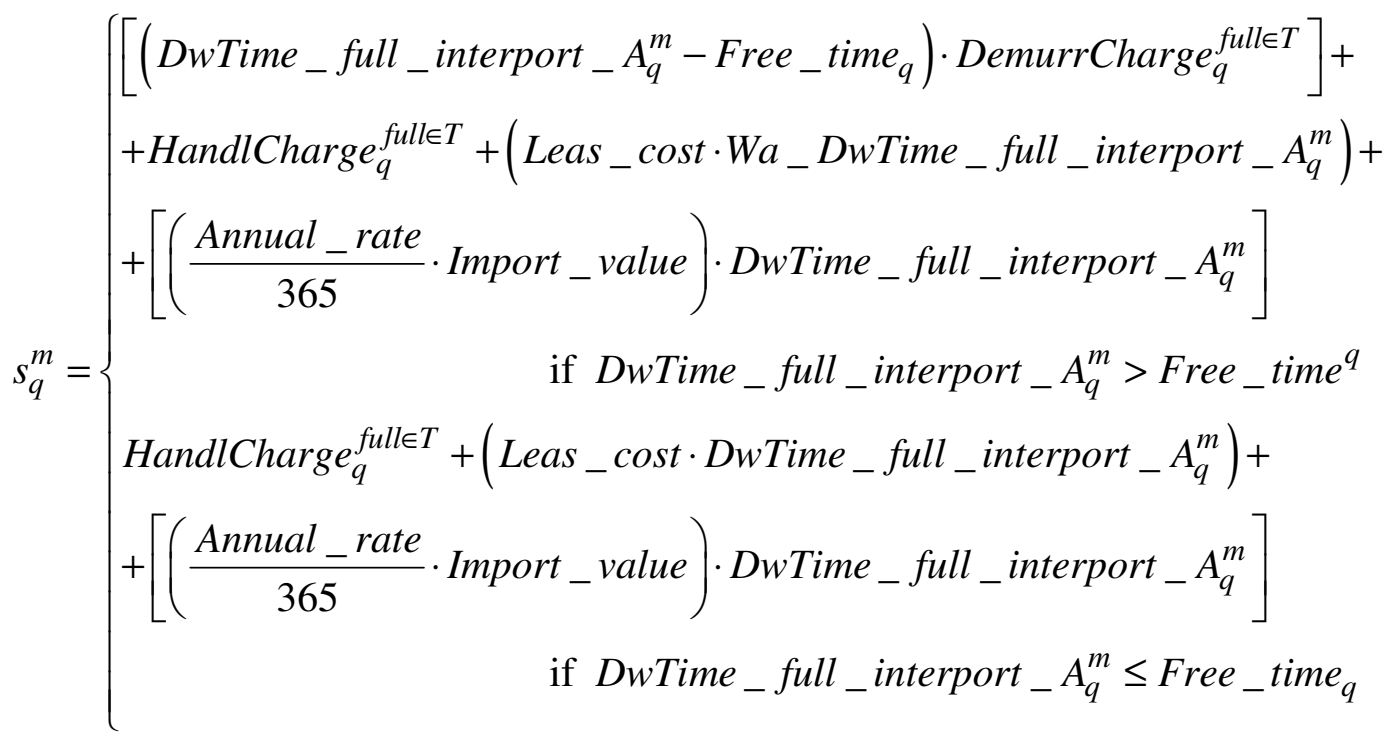


$\left[u_{p d}^{m}\right]$ : vector of weighted average total generalized unit interport costs (in Euros/TEU) of the release operations for full containers arriving to virtual interport node $d \in D$ from seaport node $p \in P$ by railway carrier haulage under customs bond (without any accompanying inland customs transit document), and subsequently leaving the same virtual interport node by transport mode $m \in M$ after customs clearance, that are calculated as

$$
\begin{aligned}
& u_{p d}^{m}=\left[\left(\frac{\text { Annual_rate }}{365} \cdot \text { Import_value }\right) \cdot W a_{-} \text {DwTime } \text { full_interport }_{p d}^{m}\right]+ \\
& +\left(\text { Leas_cost } \cdot W a_{-} \text {DwTime_full_interport }{ }_{p d}^{m}\right)+ \\
& +\sum_{\text {customs } 2 \in \text { Customs } 2}\left(\text { Interport_dir_cost } 1_{d}^{\text {customs } 2, m} \cdot \text { Ratio_interport }_{d p}^{\text {customs } 2}\right)+ \\
& +\sum_{\text {customs } 3 \in \text { Customs } 3}\left(\text { Interport_dir_cost } 2_{d}^{\text {customs } 3, m} \cdot \text { Ratio_interport }_{d p}^{\text {customs } 3}\right)
\end{aligned}
$$

$[$ WKNOTRIDIR $]$ : vector of maximal numbers of one-way weekly trains operated by railway service $a \in A$

$\left[M X N O T E U 1 T R_{a}\right]:$ vector of maximal numbers of containers (expressed in TEU) per one-way trip by railway service $a \in A$

OPWEEKYEAR: scalar representing the number of railway operational weeks in a year $\left[b_{a}\right]$ : vector of maximal numbers of containers (in TEU) that can be transported by one-way railway service $a \in A$, that are calculated as

$b_{a}=$ OPWEEKYEAR $\cdot W K N O T R 1 D I R_{a} \cdot M X N O T E U 1 T R_{a}$

\section{Endogenous variables:}

$\left[x_{i j}^{t m}\right]$ : vector of inland shipments of containers of type $t \in T$ (measured in TEU) disembarked at the seaport $l \in P$ and forwarded between nodes $i \in I$ and $j \in I$ by transport mode $m \in M$

The stylized primal inward interport problem incorporating transport external costs reads:

$\min W=$

$$
\begin{aligned}
& =\sum_{t \in T} \sum_{m \in M} \sum_{i \in I} \sum_{j \in I}\left(c_{i j}^{t m} \cdot x_{i j}^{t m}\right)+\sum_{m \in M} \sum_{n \in N} \sum_{i \in I}\left(f_{n} \cdot x_{n i}^{\text {empty } \in T, m}\right)+\sum_{m \in M} \sum_{p \in P} \sum_{z \in Z}\left(g_{p}^{m} \cdot x_{p z}^{\text {full } \in T, m}\right)+ \\
& +\sum_{p \in P} \sum_{d \in D}\left(k_{p} \cdot x_{p d}^{f u l l \in T, \text { rail } \in M}\right)+\sum_{m \in M} \sum_{q \in Q} \sum_{e \in E}\left(s_{q}^{m} \cdot x_{q e}^{f u l l \in T, m}\right)+ \\
& +\sum_{d \in D}\left[\sum_{z \in Z}\left(u_{l \in P, d}^{\text {truck } \in M} \cdot x_{d z}^{\text {fulleT, truck } \in M}\right)+\sum_{e \in E}\left(u_{l \in P, d}^{\text {rail } \in M} \cdot x_{d e}^{f u l l \in T, \text { rail } \in M}\right)\right]
\end{aligned}
$$

subject to:

$$
\begin{array}{ll}
-\sum_{i \in I} \sum_{m \in M} x_{p i}^{t m} \geq- \text { Demand }_{l \in P, p}^{t} & \text { for all } t \in T \text { and } p \in P \\
\sum_{m \in M} \sum_{i \in I} x_{i h}^{t m}-\sum_{m \in M} \sum_{i \in I} x_{h i}^{t m} \geq \text { Demand }_{l \in P, h}^{t} & \text { for all } t \in T \text { and } h \in H
\end{array}
$$




$$
\begin{aligned}
& \sum_{m \in M} \sum_{i \in I} x_{i r}^{t m} \geq \text { Demand }_{l \in P, r}^{t} \\
& \sum_{t \in T}\left(x_{l \in P, 2 \in Q}^{t, r a i l \in M}+x_{l \in P, 3 \in D}^{t, r a i l \in M}\right) \leq b_{1 \_(2+3) \in A} \\
& \sum_{t \in T} x_{l \in P, 4 \in Z}^{t, \text { rail } \in M} \leq b_{1 \_4 \in A} \\
& \sum_{t \in T}\left(x_{2 \in Q, 4 \in Z}^{t, \text { rail } \in M}+x_{3 \in D, 4 \in Z}^{t, r a i l \in M}\right) \leq b_{(2+3) \_4 \in A} \\
& \sum_{t \in T}\left(x_{2 \in Q, 5 \in Z}^{t, \text { rail } \in M}+x_{3 \in D, 5 \in Z}^{t, \text { raileM }}\right) \leq b_{(2+3) \_5 \in A} \\
& x_{i j}^{t m} \geq 0 \\
& x_{i j}^{t m}=0 \\
& x_{3 \in D, 2 \in Q}^{f u l l \in T, \text { truck } \in M} \geq 0
\end{aligned}
$$$$
\text { for all } t \in T \text { and } r \in R
$$

The sets $Q$ and $D$ represent virtual interport nodes. A full container arriving at a seaport node $p \in P$ can either be cleared by the customs right away, in which case it can proceed to an inland demanding location $z \in Z$, including virtual interport nodes without customs function ( $q \in Q \subseteq Z$ ). Or it can have its customs clearance delayed, in which case it has to proceed by railway to a virtual interport node with customs function $d \in D$. In this manner, shippers may avoid costly delays in seaport awaiting access to customs clearance.

The railway services to/from the interport include the connections to/from each of the two corresponding virtual nodes. For instance, the rail service from the seaport node 1 to the interport is symbolically represented by ' $1 \_(2+3)$ ', which means that such service carries containers from node 1 to node 2 and node 3 , simultaneously. In the same manner, the rail service from the interport to the location 5 is symbolically represented by ' $(2+3) \_5$ ', which means that such service carries containers simultaneously from node 2 to node 5 and from node 3 to node 5 .

The demand specified by 'origin node-origin node' pair (i.e. Demand ${ }_{p p}^{t}$ for all $t \in T$ and $p \in P$ ) indicates the total container supply available at the specific port node $p \in P$, and is entered in the model with the minus sign in order to write the flow conservation constraint (2) with a $\geq$ sign.

The critical cost items explicitly taken into account by the model are:

- container handling costs;

- container storage costs, in function both of the demurrage charge and of the dwell time exceeding the free time provided by terminal companies at seaports and interports;

- additional direct costs for physical inspection and X-ray scanner control by customs at seaports and interports;

- in-transit inventory holding costs, in function of the customs declared value of cargoes, the time duration of distribution operations, and a reference interest rate reflecting both the opportunity cost of the capital tied in containerized goods and the economic-technical depreciation costs of the same goods;

- container leasing costs, in function both of a container leasing charge and of the time duration of distribution operations;

- internal transport costs;

- external transport costs (climate change, air and nose pollution, accidents, congestion).

In the objective function (1) such cost items are compressed into aggregated parameters $(c, f, g, k$, $s$, and $u$ ). Furthermore, the internal costs of transport either by road or railway toward generic nodes include the terminal operation costs related to the offloading of the container from the vehicle at the 
end of the trip. The internal costs of road transport from inland nodes featuring a railway terminal (excluding the interport nodes) to demand nodes not so equipped comprise the costs of terminal operations both at the departure and at the arrival.

Total travel times by road over admitted links are equal to the driving time both on motorways and on other road types plus the time for rests and stops prescribed by Road regulations. Road driving times are computed by assuming two different admitted truck's average speeds over motorways and other road types. The number and time duration of rests and stops need to be calculated as a function of the driving time ${ }^{7}$. As for total travel times by rail over admitted links, these are instead purely exogenous.

The weighted average total generalized unit port and interport costs of release operations for cleared full containers (i.e. the $g$ and $u$ parameters) are computed by taking into consideration both direct costs (for terminal and customs operations) ${ }^{8}$ and time-related indirect costs (for inventory holding and container leasing), according to the different probabilities observed in the seaport $p$ for the different types of customs control ${ }^{9}$.

The capacity limits of railway services (i.e. the $b$ parameters) are computed by taking into account: i) the number of railway operational weeks in the planning period, ii) the number of weekly trains operated by each service $a \in A$, and iii) the maximal number of containers per trip of the same service.

The objective function (1) denotes the total social generalized logistic cost for the distribution of imported full and empty containers throughout the port hinterland network. The first term represents the total social cost for rail and road transportation over the network. The second term indicates the total release cost for empty containers at seaport and interport nodes. The third term denotes the total release cost for full containers cleared by customs at the seaport and leaving by road and railway. The fourth term indicates the total release cost for full containers leaving the seaport by railway under customs bond on behalf of shipping lines and without any accompanying inland customs transit document. The containers will be subsequently cleared by customs at the interports. The fifth term of the function is the total release cost for full containers already cleared in the seaport, entering the interports, and leaving the same interports by road and railway. Finally, the sixth term represents the total release cost for full containers cleared by customs at the interports, and leaving the same interports by road and railway

Flow conservation at the origin node requires that the supply at the node must suffice to cover the flows leaving the same node (constraint (2)). For intermediate nodes the balancing conditions state that the flow entering each node must suffice to cover the flows leaving it (constraints represented by (3)). Finally, for each destination node, the deliveries forthcoming at the node must suffice to cover demand (constraints represented by (4)).

Capacity constraints of the railway connections are (5)-(8). The limit of each connection towards/from the interport jointly considers the railway services towards/from each of the two corresponding virtual nodes (in (5), (7), (8)).

Non-negativity constraints on the primal endogenous variables are represented by (9). They state that the variables cannot assume negative values. In addition, the conditions represented by (10) set

\footnotetext{
${ }^{7}$ See, for instance, the computational procedure employed by Aponte et al. (2009) with regard to freight transport on Italian roads.

${ }^{8}$ The terminal pricing structure at seaports and interports can be much more articulated and diversified than that modelled in the primal program presented above. Demurrage fees are usually charged by terminal operators on a sliding scale. In addition, such charges may generally vary among different terminals located in the same seaport or interport, and also according to specific agreements among service providers and customers (i.e. terminal companies, shipping lines and shippers). The interport model may easily simulate whatever type of terminal pricing structure. ${ }^{9}$ For simplification and illustrative purposes, in the interport model it is assumed that all the container transiting through the seaports of the investigated regional logistic system carry legitimate cargoes, and therefore succeed in positively passing the customs controls. Moreover, the model does not take into consideration the payment of customs duties related to the traded goods' value.
} 
to zero all variables involving non-existing links of the logistic network ${ }^{10}$. Finally, the constraint (11) permits one-way road transport with a nil generalized cost for full containers between the two virtual interport nodes, that is the road transport between $3 \in D$ and $2 \in Q$.

\subsection{The dual programming model}

When a direct programming problem is one of cost minimization, the dual program is one of maximizing value. The dual program of the interport model maximizes the total net appreciation of container flows' shadow value cumulating in the network, while also including the shadow value of rail services' capacity constraints. The problem is subjected to the conditions that the value appreciation created along each and every link be exhausted by its costs; in addition, there are both non-negativity and non-positivity constraints on endogenous variables.

In the primal interport problem there is a given supply of full and empty containers at each seaport, and a given demand at each inland location (excluding the virtual interport nodes with customs function); furthermore, there are intermediate transhipment nodes (also including all virtual interport nodes) and capacity limits of railway services. Accordingly, in the dual interport problem, there are shadow prices for each type of traffic flows (i.e. flows of full and empty containers) implied at the nodes of the investigated network. These dual variables measure the value or worth of relaxing the corresponding flow conservation constraints by one unit, and they can be arranged as the vector $\left[v_{i}^{t}\right]$ for all $t \in T$ and $i \in I$. Also, the dual problem features shadow prices of railway capacity constraints. These parameters can be arranged as the vector [ $\left.s c c_{a}\right]$ for all $a \in A$, and are interpreted as imputed costs assessed on container shipments along the concerned rail services.

The dual inward interport problem reads:

$\max Z=$

$-\sum_{p \in P} \sum_{t \in T}\left(v_{p}^{t} \cdot\right.$ Demand $\left._{p p}^{t}\right)+\sum_{i \neq p \in I} \sum_{p \in P} \sum_{t \in T}\left(v_{i}^{t} \cdot\right.$ Demand $\left._{p i}^{t}\right)+\sum_{a \in A}\left(\operatorname{scc}_{a} \cdot b_{a}\right)$

subject to:

$$
\begin{aligned}
& -v_{l \in P}^{\text {full } \in T}+v_{z}^{\text {full } \in T} \leq c_{l \in P, z}^{\text {full } \in T, \text { truck } \in M}+g_{l \in P}^{\text {truck } \in M} \quad \text { for all } z \in Z \\
& -v_{l \in P}^{\text {full } \in T}+v_{2 \in Q}^{\text {full } \in T}+s c c_{1 \_(2+3) \in A} \leq c_{l \in P, 2 \in Q}^{\text {full } \in T, \text { rail } \in M}+g_{l \in P}^{\text {rail } \in M} \\
& -v_{l \in P}^{\text {full } \in T}+v_{3 \in D}^{\text {full } \in T}+s c c_{1 \_(2+3) \in A} \leq c_{l \in P, 3 \in D}^{\text {full } \in T, \text { rail } \in M}+k_{l \in P} \\
& -v_{l \in P}^{\text {full } \in T}+v_{4 \in E}^{\text {full } \in T}+s c c_{1 \_4 \in A} \leq c_{l \in P, 4 \in E}^{\text {full } \in T, \text { rail } \in M}+g_{l \in P}^{\text {rail } \in M} \\
& -v_{2 \in Q}^{\text {full } \in T}+v_{e}^{\text {full } \in T} \leq c_{2 \in Q, e}^{\text {full } \in T, \text { truck } \in M}+s_{2 \in Q}^{\text {truck } \in M} \quad \text { for all } e \in E \\
& -v_{2 \in Q}^{f u l l \in T}+v_{4 \in E}^{\text {full } \in T}+\operatorname{scc}_{(2+3) \_4 \in A} \leq c_{2 \in Q, 4 \in E}^{\text {full } \in T, \text { rail } \in M}+s_{2 \in Q}^{\text {rail } \in M}
\end{aligned}
$$

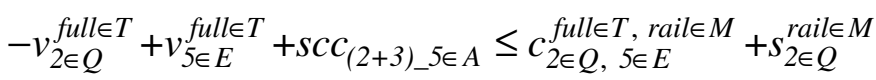

$$
\begin{aligned}
& -v_{3 \in D}^{\text {full } \in T}+v_{z}^{\text {full } \in T} \leq c_{3 \in D, z}^{\text {full } \in T, \text { truck } \in M}+u_{3 \in D}^{\text {truck } \in M} \quad \text { for all } z \in Z \\
& -v_{3 \in D}^{\text {full } \in T}+v_{4 \in E}^{f u l l \in T}+s c c_{(2+3) \_4 \in A} \leq c_{3 \in D, 4 \in E}^{f u l l \in T, \text { rail } \in M}+u_{3 \in D}^{\text {rail } \in M}
\end{aligned}
$$

\footnotetext{
${ }^{10}$ Similarly to all the large-scale network models, also the interport model uses a sparse data structure, that is a structure based on data matrices with relatively few non-zero entries. It seems appropriate to remember and highlight the fact that (road and/or railway) connections are not allowed between some nodes of the network investigated by the model. Therefore, a value equal to zero has to be assigned to the spatial, temporal and economic attributes of forbidden links, and appropriate constraints have to be formulated accordingly.
} 


$$
\begin{aligned}
& -v_{3 \in D}^{\text {full } \in T}+v_{5 \in E}^{\text {full } \in T}+s c c_{(2+3) \_5 \in A} \leq c_{3 \in D, 5 \in E}^{\text {full } \in T, \text { rail } \in M}+u_{3 \in D}^{\text {rail } \in M} \\
& -v_{e}^{f u l l \in T}+v_{e^{\prime}}^{f u l l \in T} \leq c_{e e^{\prime}}^{f u l l \in T, \text { truck } \in M} \\
& -v_{5 \in E}^{f u l l \in T}+v_{6 \in E}^{\text {full } \in T} \leq c_{5 \in E, 6 \in E}^{\text {fulleT, truck } \in M} \\
& -v_{l \in P}^{\text {empty } \in T}+v_{z}^{\text {empty } \in T} \leq c_{l \in P, z}^{\text {empty } \in T, \text { truck } \in M}+f_{l \in P} \quad \text { for all } z \in Z \\
& -v_{l \in P}^{e m p t y \in T}+v_{2 \in Q}^{e m p t y \in T}+s c c_{1 \_(2+3) \in A} \leq c_{l \in P, 2 \in Q}^{e m p t y \in T, \text { rail } \in M}+f_{l \in P} \\
& -v_{l \in P}^{e m p t y \in T}+v_{4 \in E}^{\text {empty } \in T}+s c c_{1 \_4 \in A} \leq c_{l \in P, 4 \in E}^{\text {empty } \in T, \text { rail } \in M}+f_{l \in P} \\
& -v_{2 \in Q}^{\text {empty } \in T}+v_{e}^{\text {empty } \in T} \leq c_{2 \in Q, e}^{\text {empty } \in T, \text { truck } \in M}+f_{2 \in Q} \quad \text { for all } e \in E \\
& -v_{2 \in Q}^{\text {empty } \in T}+v_{4 \in E}^{\text {empty } \in T}+s c c_{(2+3) \_4 \in A} \leq c_{2 \in Q, 4 \in E}^{\text {empty } \in T, \text { rail } \in M}+f_{2 \in Q} \\
& -v_{2 \in Q}^{\text {empty } \in T}+v_{5 \in E}^{\text {empty } \in T}+s c c_{(2+3) \_5 \in A} \leq c_{2 \in Q, 5 \in E}^{\text {empty } \in T \text {, rail } \in M}+f_{2 \in Q} \\
& -v_{e}^{e m p t y \in T}+v_{e^{\prime}}^{e m p t y \in T} \leq c_{e e^{\prime}}^{\text {empty } \in T, \text { truck } \in M}
\end{aligned}
$$

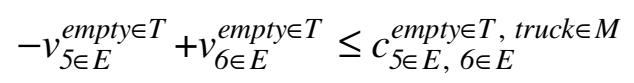

$$
\begin{aligned}
& v_{i}^{t} \geq 0 \\
& \operatorname{scc}_{a} \leq 0 \\
& \text { for all } e=4,5 \in E \\
& \text { and } e^{\prime}=5,4 \in E
\end{aligned}
$$

In the dual objective function (12), the total shadow cost the container flows entering the network is $\sum_{p \in P} \sum_{t \in T}\left(v_{p}^{t} \cdot\right.$ Demand $\left._{p p}^{t}\right)$. The total shadow value of the container flows leaving out the final destinations is $\sum_{i \neq p \in I} \sum_{p \in P} \sum_{t \in T}\left(v_{i}^{t} \cdot\right.$ Demand $\left._{p i}^{t}\right)$. The total shadow value of rail capacity in the network is $\sum_{a \in A}\left(s c c_{a} \cdot b_{a}\right)$

Furthermore, there are the dual constraints represented by (13)-(32). There is one dual constraint for each and every modal link in the network. It states an important principle that is referred to as 'exhaustion of value'. Along any positive road flow in the network, the increase in shadow value (that is the difference between the shadow price at destination $v_{j}$ and the shadow cost at origin $v_{i}$ ) must be exactly exhausted by the total social unit logistic cost of the shipment. Instead, along any positive rail flow in the network, the imputed appreciation $-v_{i}+v_{j}$ along the rail link plus the shadow price of the capacity limit must be exactly exhausted by the total social unit logistic cost of the shipment. That is, all cumulating values must have a source that can be accounted for. No free value can arise.

Consider for example the road link for the transfer of containers from node 1 to node 2 in Figure 1 . The shadow cost of the flow at node 1 is $v_{1}^{\text {full }}$; the shadow price of the flow at node 2 is $v_{2}^{\text {full }}$. The exhaustion of value condition then states $-v_{1}^{\text {full }}+v_{2}^{\text {full }} \leq c_{12}^{\text {full, truck }}+g_{1}^{\text {truck }}$, i.e. the dual price at node 2 cannot exceed the dual price at node 1 plus the unit logistic cost $c_{12}^{\text {full, truck }}+g_{1}^{\text {truck }}$. Actually, if there is a positive road transportation flow along the link, the shadow price at node 2 must equal the shadow price at node 1 plus the logistic cost. A hypothetical logistic agent shipping containers from node 1 to node 2 will then break exactly even. But there is also the possibility that the shadow value at node 2 falls short of the shadow cost at node 1 plus the the logistic cost. In that case, the shipper would suffer an imputed loss and the shipment is not worth his while. No road shipment will take 
place. In general, optimality requires nonnegative shipments' reduced costs equalling the slack values in exhaustion of value constraints.

The additional dual constraints represented by (33) impose that the shadow prices of the traffic flows implied at the nodes of the network have to be nonnegative. What this means is that the shipped container at some nodes may be 'scarce', i.e. commands a positive shadow price. Or the container may be a 'free good', in which case the shadow price is zero. This happens if there is a buildup of unwanted container inventory at the node, so that an excess availability is created. The ultimate dual constraints represented by (34) requires that shadow prices of railway capacity constraints have to be nonpositive.

Finally, the optimal value of the dual objective function (12) is unique and equals the optimal value of the primal function (1). Here one encounters the principle of exhaustion of value again. The total increase in shadow value over the network equals the total social logistic cost of port hinterland container distribution. This is the 'fundamental theorem of duality' in linear programming: the optimal value of the direct problem equals the optimal value of the dual problem.

\subsection{Primal and dual complementary slackness conditions of the interport model}

The primal and dual programs of the interport model are tied to each other according complementing properties which can be stated in the form of the following six propositions of complementary slackness, to be held at the point of optimum:

i) If it turns out that there are excess deliveries of container flow at any node, the shadow price at that node vanishes. The transported container is then a free good at the node.

ii) But if the container at the node is scarce, i.e. if it commands a positive shadow price, then outflow from the node exactly equals the total inflow into the node.

iii) If a rail link has surplus capacity, then the imputed surcharge assessed on shipments along such link is zero which makes unused transportation capacity on that route a free good.

iv) But if all the capacity on a rail link is used, then the imputed surcharge assessed on shipments along such link is less then zero, that is there is a surcharge on the use of the link. If the shadow value appreciation of container shipments along a link in the network (plus the shadow price of link capacity constraint, if applicable) falls short of the total social unit logistic cost, the flow along this link is zero. A hypothetical shipper would suffer a unit loss so he withdraws.

v) But if a positive flow occurs along the link, then the appreciation of shadow value of container shipments (plus the shadow price of capacity constraint, if applicable) must exactly equal the unit cost. A hypothetical shipper finds that his costs are exactly covered. These complementary slackness conditions connect pairs of optimal basic feasible solution of the primal and dual programs of the model.

Optimal dual variables $v^{*}$ are associated to binding flow conservation constraints of the primal problem. Hence, it is required that at the optimum of the interport problem they satisfy the following primal complementary slackness conditions (35)-(38) containing the propositions i) and ii) listed above:

$-\sum_{m \in M} \sum_{i \in I} x_{p i}^{t m^{*}}+$ Demand $_{l \in P, p}^{t} \geq 0$

and

$$
v_{p}^{t^{*}} \cdot\left(-\sum_{m \in M} \sum_{i \in I} x_{p i}^{t m^{*}}+\text { Demand }_{I \in P, p}^{t}\right)=0
$$

for all $t \in T$ and $p \in P$

$\sum_{m \in M} \sum_{i \in I} x_{i h}^{t m^{*}}-\sum_{m \in M} \sum_{i \in I} x_{h i}^{t m^{*}}-$ Demand $_{l \in P, h}^{t} \geq 0 \quad$ and

$v_{h}^{t^{*}} \cdot\left(\sum_{m \in M} \sum_{i \in I} x_{i h}^{t m^{*}}-\sum_{m \in M} \sum_{i \in I} x_{h i}^{t m^{*}}-\right.$ Demand $\left._{l \in P, h}^{t}\right)=0 \quad$ for all $t \in T$ and $h \in H$ 
$\sum_{m \in M} \sum_{i \in I} x_{i r}^{t m^{*}}-$ Demand $_{l \in P, r}^{t} \geq 0$

and $\quad v_{r}^{t^{*}} \cdot\left(\sum_{m \in M} \sum_{i \in I} x_{i r}^{t m^{*}}-\right.$ Demand $\left._{l \in P, r}^{t}\right)=0$

for all $t \in T$ and $r \in R$

$v_{i}^{t^{*}} \geq 0 \quad$ for all $t \in T$ and $i \in I$

Because of the railway capacity constraints in the primal program, at the optimum of the problem the following complementary slackness conditions (39)-(43) containing the propositions iii) and iv) listed above must be satisfied as well:

$$
\begin{aligned}
& \sum_{t \in T}\left(x_{1 \in P, 2 \in Q}^{t, \text { rail } \in M^{*}}+x_{1 \in P, 3 \in D}^{t, \text { rail } \in M^{*}}\right)-b_{1 \_(2+3) \in A} \leq 0 \quad \text { and } \\
& \operatorname{scc}_{1 \_(2+3) \in A}^{*} \cdot\left[\sum_{t \in T}\left(x_{l \in P, 2 \in Q}^{t, r a i l \in M^{*}}+x_{l \in P, 3 \in D}^{t, r a i l \in M^{*}}\right)-b_{1 \_(2+3) \in A}\right]=0 \\
& \sum_{t \in T} x_{l \in P, 4 \in Z}^{t, r a i l \in M^{*}}-b_{1 \_4 \in A} \leq 0 \\
& \text { and } \quad \operatorname{scc}_{1_{-} \_\in A}^{*} \cdot\left(\sum_{t \in T} x_{i \in P, 4 \in Z}^{t, r a i l \in M^{*}}-b_{1 \_4 \in A}\right)=0
\end{aligned}
$$

$\sum_{t \in T}\left(x_{2 \in Q, 4 \in Z}^{t, \text { rail } \in M^{*}}+x_{3 \in D, 4 \in Z}^{t, \text { rail } \in M^{*}}\right)-b_{(2+3) \_4 \in A} \leq 0 \quad$ and

$\operatorname{scc}_{(2+3) \_4 \in A}^{*} \cdot\left[\sum_{t \in T}\left(x_{2 \in Q, 4 \in Z}^{t, \text { rail } \in M^{*}}+x_{3 \in D, 4 \in Z}^{t, \text { rail } \in M^{*}}\right)-b_{(2+3) \_4 \in A}\right]=0$

$\sum_{t \in T}\left(x_{2 \in Q, 5 \in Z}^{t, \text { rail } \in M^{*}}+x_{3 \in D, 5 \in Z}^{t, \text { rail } \in M^{*}}\right)-b_{(2+3) \_5 \in A} \leq 0 \quad$ and

$\operatorname{scc}_{(2+3) \_5 \in A}^{*} \cdot\left[\sum_{t \in T}\left(x_{2 \in Q, 5 \in Z}^{t, \text { rail } \in M^{*}}+x_{3 \in D, 5 \in Z}^{t, r a i l \in M^{*}}\right)-b_{(2+3) \_5 \in A}\right]=0$

$s c c_{a}^{*} \leq 0 \quad$ for all $a \in A$

Finally, there are the following 'dual complementary slackness conditions' (44)-(64) to hold at the point of optimum and which contain the propositions v) and vi) listed above:

$$
\begin{aligned}
& c_{l \in P, z}^{f u l l \in T, \text { truck } \in M}+g_{l \in P}^{\text {truck } \in M}+v_{l \in P}^{f u l l \in T^{*}}-v_{z}^{\text {full } \in T^{*}} \geq 0 \quad \text { and } \\
& x_{l \in P, z}^{f u l l \in T, \text { truck } \in M^{*}} \cdot\left(c_{l \in P, z}^{f u l l \in T, \text { truck } \in M}+g_{l \in P}^{\text {truck } \in M}+v_{l \in P}^{f u l l \in T^{*}}-v_{z}^{f u l l \in T^{*}}\right)=0 \quad \text { for all } z \in Z \\
& c_{l \in P, 2 \in Q}^{f u l l \in T, \text { rail } \in M}+g_{l \in P}^{\text {rail } \in M}+v_{l \in P}^{f u l l \in T^{*}}-v_{2 \in Q}^{f u l l \in T^{*}}-s c c_{1 \_(2+3) \in A}^{*} \geq 0 \quad \text { and } \\
& x_{l \in P, 2 \in Q}^{f u l l \in T, \text { rail } \in M^{*}} \cdot\left(c_{l \in P, 2 \in Q}^{f u l l \in T, \text { rail } \in M}+g_{l \in P}^{\text {rail } \in M}+v_{l \in P}^{f u l l \in T^{*}}-v_{2 \in Q}^{f u l l \in T^{*}}-s c c_{1 \_(2+3) \in A}^{*}\right)=0 \\
& c_{l \in P, 3 \in D}^{f u l l \in T, \text { rail } \in M}+k_{l \in P}+v_{l \in P}^{f u l l \in T^{*}}-v_{3 \in D}^{f u l l \in T^{*}}-s c c_{1 \_(2+3) \in A}^{*} \geq 0 \\
& \text { and } \\
& x_{l \in P, 3 \in D}^{f u l l \in T, \text { rail } \in M^{*}} \cdot\left(c_{l \in P, 3 \in D}^{f u l l \in T, \text { rail } \in M}+k_{l \in P}+v_{l \in P}^{f u l l \in T^{*}}-v_{3 \in D}^{f u l l \in T^{*}}-S c c_{1 \_(2+3) \in A}^{*}\right)=0 \\
& c_{l \in P, 4 \in E}^{f u l l \in T, \text { rail } \in M}+g_{l \in P}^{\text {rail } \in M}+v_{l \in P}^{f u l l \in T^{*}}-v_{4 \in E}^{f u l l \in T^{*}}-\operatorname{scc}_{1 \_4 \in A}^{*} \geq 0
\end{aligned}
$$

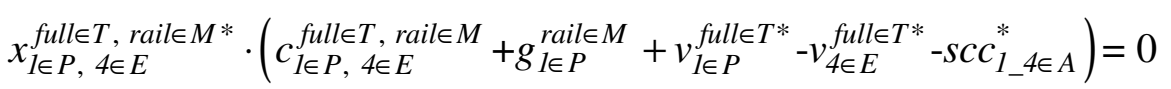


$c_{2 \in Q, e}^{f u l l \in T, \text { truck } \in M}+s_{2 \in Q}^{\text {truckeM }}+v_{2 \in Q}^{\text {full } \in T^{*}}-v_{e}^{f u l l \in T^{*}} \geq 0 \quad$ and

$x_{2 \in Q, e}^{f u l l \in T, \text { truck } \in M^{*}} \cdot\left(c_{2 \in Q, e}^{\text {full } \in T, \text { truck } \in M}+s_{2 \in Q}^{\text {truck } \in M}+v_{2 \in Q}^{f u l l \in T^{*}}-v_{e}^{f u l l \in T^{*}}\right)=0 \quad$ for all $e \in E$

$c_{2 \in Q, 4 \in E}^{f u l l \in T, \text { rail } \in M}+s_{2 \in Q}^{\text {rail } \in M}+v_{2 \in Q}^{f u l l \in T^{*}}-v_{4 \in E}^{f u l l \in T^{*}}-\operatorname{scc}_{(2+3) \_4 \in A}^{*} \geq 0 \quad$ and

$x_{2 \in Q, 4 \in E}^{f u l l \in T, \text { rail } \in M^{*}} \cdot\left(c_{2 \in Q, 4 \in E}^{f u l l \in T, \text { rail } \in M}+s_{2 \in Q}^{\text {rail } \in M}+v_{2 \in Q}^{f u l l \in T^{*}}-v_{4 \in E}^{f u l l \in T^{*}}-\operatorname{scc}_{(2+3) \_4 \in A}^{*}\right)=0$

$c_{2 \in Q, 5 \in E}^{f u l l \in T, \text { rail } \in M}+s_{2 \in Q}^{\text {rail } \in M}+v_{2 \in Q}^{f u l l \in T^{*}}-v_{5 \in E}^{\text {full } \in T^{*}}-\operatorname{scc}_{(2+3) \_5 \in A}^{*} \geq 0 \quad$ and

$x_{2 \in Q, 5 \in E}^{f u l l \in T, \text { rail } \in M^{*}} \cdot\left(c_{2 \in Q, 5 \in E}^{\text {full } \in T, \text { rail } \in M}+s_{2 \in Q}^{\text {rail } \in M}+v_{2 \in Q}^{f u l l \in T^{*}}-v_{5 \in E}^{f u l l \in T^{*}}-s c c_{(2+3) \_5 \in A}^{*}\right)=0$

$c_{3 \in D, z}^{f u l l \in T, \text { truck } \in M}+u_{3 \in D}^{\text {truck } \in M}+v_{3 \in D}^{\text {full } \in T^{*}}-v_{z}^{\text {full } \in T^{*}} \geq 0$

and

$x_{3 \in D, z}^{\text {full } \in T, \text { truck } \in M^{*}} \cdot\left(c_{3 \in D, z}^{\text {full } \in T, \text { truck } \in M}+u_{3 \in D}^{\text {truck } \in M}+v_{3 \in D}^{f u l l \in T^{*}}-v_{z}^{f u l l \in T^{*}}\right)=0$

for all $z \in Z$

$c_{3 \in D, 4 \in E}^{f u l l \in T, \text { rail } \in M}+u_{3 \in D}^{\text {rail } \in M}+v_{3 \in D}^{f u l l \in T^{*}}-v_{4 \in E}^{f u l l \in T^{*}}-\operatorname{scc}_{(2+3) \_4 \in A}^{*} \geq 0$

and

$x_{3 \in D, 4 \in E}^{f u l l \in T, \text { rail } \in M^{*}} \cdot\left(c_{3 \in D, 4 \in E}^{f u l l \in T, \text { rail } \in M}+u_{3 \in D}^{\text {rail } \in M}+v_{3 \in D}^{f u l l \in T^{*}}-v_{4 \in E}^{f u l l \in T^{*}}-s c c_{(2+3) \_4 \in A}^{*}\right)=0$

$c_{3 \in D, 5 \in E}^{f u l l \in T, \text { rail } \in M}+u_{3 \in D}^{\text {rail } \in M}+v_{3 \in D}^{f u l l \in T^{*}}-v_{5 \in E}^{f u l l \in T^{*}}-\operatorname{scc}_{(2+3) \_5 \in A}^{*} \geq 0$

and

$x_{3 \in D, 5 \in E}^{\text {full } \in T, \text { rail } \in M^{*}} \cdot\left(c_{3 \in D, 5 \in E}^{\text {full } \in T, \text { rail } \in M}+u_{3 \in D}^{\text {rail } \in M}+v_{3 \in D}^{\text {full } \in T^{*}}-v_{5 \in E}^{\text {full } \in T^{*}}-\operatorname{scc}_{(2+3) \_5 \in A}^{*}\right)=0$

$c_{e e^{\prime}}^{f u l l \in T, \text { truck } \in M}+v_{e}^{f u l l \in T^{*}}-v_{e^{\prime}}^{f u l l \in T^{*}} \geq 0$

and

$x_{e e^{\prime}}^{f u l l \in T, \text { truck } \in M^{*}} \cdot\left(c_{e e^{\prime}}^{f u l l \in T, \text { truck } \in M}+v_{e}^{f u l l \in T^{*}}-v_{e^{\prime}}^{f u l l \in T^{*}}\right)=0 \quad$ for all $e=4,5 \in E$ and $e^{\prime}=5,4 \in E$

$c_{5 \in E, 6 \in E}^{f u l l \in T, \text { truck } \in M}+v_{5 \in E}^{\text {full } \in T^{*}}-v_{6 \in E}^{f u l l \in T^{*}} \geq 0$

and

$x_{5 \in E, 6 \in E}^{f u l l \in T, \text { truck } \in M^{*}} \cdot\left(c_{5 \in E, 6 \in E}^{f u l l \in T, \text { truck } \in M}+v_{5 \in E}^{f u l l \in T^{*}}-v_{6 \in E}^{f u l l \in T^{*}}\right)=0$

$c_{l \in P, z}^{\text {empty } \in T, \text { truck } \in M}+f_{l \in P}+v_{l \in P}^{\text {empty } \in T^{*}}-v_{z}^{\text {empty } \in T^{*}} \geq 0$

and

$x_{l \in P, z}^{\text {empty } \in T, \text { truck } \in M^{*}} \cdot\left(c_{l \in P, z}^{\text {empty } \in T, \text { truck } \in M}+f_{l \in P}+v_{l \in P}^{\text {empty } \in T^{*}}-v_{z}^{\text {empty } \in T^{*}}\right)=0 \quad$ for all $z \in Z$

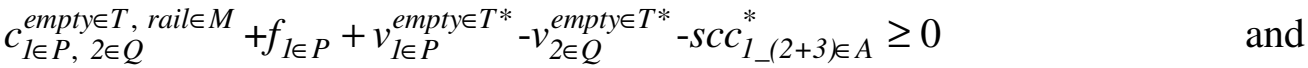

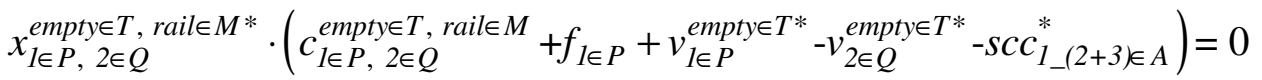

$c_{l \in P, 4 \in E}^{\text {empty } \in T, \text { rail } \in M}+f_{l \in P}+v_{l \in P}^{\text {empty } \in T^{*}}-v_{4 \in E}^{\text {empty } \in T^{*}}-s c c_{1 \_4 \in A}^{*} \geq 0$

and

$x_{l \in P, 4 \in E}^{\text {empty } \in T, \text { rail } \in M^{*}} \cdot\left(c_{l \in P, 4 \in E}^{\text {empty } \in T, \text { rail } \in M}+f_{l \in P}+v_{l \in P}^{\text {empty } \in T^{*}}-v_{4 \in E}^{\text {empty } \in T^{*}}-s c c_{1 \_4 \in A}^{*}\right)=0$

$c_{2 \in Q, e}^{\text {empty } \in T, \text { truck } \in M}+f_{2 \in Q}+v_{2 \in Q}^{\text {empty } \in T^{*}}-v_{e}^{\text {empty } \in T^{*}} \geq 0$

and

$x_{2 \in Q, e}^{\text {full } \in T, \text { truck } \in M^{*}} \cdot\left(c_{2 \in Q, e}^{\text {empty } \in T, \text { truck } \in M}+f_{2 \in Q}+v_{2 \in Q}^{\text {empty } \in T^{*}}-v_{e}^{\text {empty } \in T^{*}}\right)=0 \quad$ for all $e \in E$

$c_{2 \in Q, 4 \in E}^{\text {empty } \in T, \text { rail } \in M}+f_{2 \in Q}^{\text {rail } \in M}+v_{2 \in Q}^{\text {empty } \in T^{*}}-v_{4 \in E}^{\text {empty } \in T^{*}}-\operatorname{scc}_{(2+3) \_4 \in A}^{*} \geq 0 \quad$ and

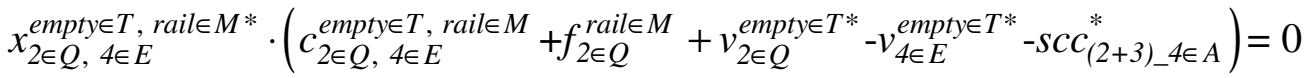

$c_{2 \in Q, 5 \in E}^{\text {empty } \in T, \text { rail } \in M}+f_{2 \in Q}^{\text {rail } \in M}+v_{2 \in Q}^{\text {empty } \in T^{*}}-v_{5 \in E}^{\text {empty } \in T^{*}}-S c c_{(2+3) \_5 \in A}^{*} \geq 0 \quad$ and

$x_{2 \in Q, 5 \in E}^{\text {empty } \in T, \text { rail } \in M^{*}} \cdot\left(c_{2 \in Q, 5 \in E}^{\text {empty } \in T, \text { rail } \in M}+f_{2 \in Q}^{\text {rail } \in M}+v_{2 \in Q}^{\text {empty } \in T^{*}}-v_{5 \in E}^{\text {empty } \in T^{*}}-\operatorname{scc}_{(2+3) \_5 \in A}^{*}\right)=0$ 
$c_{e e^{\prime}}^{\text {empty } \in T, \text { truck } \in M}+v_{e}^{\text {empty } \in T^{*}}-v_{e^{\prime}}^{\text {empty } \in T^{*}} \geq 0$
$x_{e e^{\prime}}^{\text {empty } \in T, \text { truck } \in M^{*}} \cdot\left(c_{e e^{\prime}}^{\text {empty } \in T, \text { truck } \in M}+v_{e}^{\text {empty } \in T^{*}}-v_{e^{\prime}}^{\text {empty } \in T^{*}}\right)=0$

and

for all $e=4,5 \in E$ and $e^{\prime}=5,4 \in E$

$c_{5 \in E, 6 \in E}^{\text {empty } \in T, \text { truck } \in M}+v_{5 \in E}^{\text {empty } \in T^{*}}-v_{6 \in E}^{\text {empty } \in T^{*}} \geq 0$

and

$x_{5 \in E, 6 \in E}^{\text {empty } \in T, \text { truck } \in M^{*}} \cdot\left(c_{5 \in E, 6 \in E}^{\text {empty } \in T, \text { truck } \in M}+v_{5 \in E}^{\text {empty } \in T^{*}}-v_{6 \in E}^{\text {empty } \in T^{*}}\right)=0$

$x_{i j}^{t m^{*}} \geq 0 \quad$ for all $t \in T, m \in M$ and $i, j \in I$

The set of disequations in (35)-(37) and (39)-(42) are simply the constraints of the direct program. The set of disequations in (44)-(63) are simply the constraints of the dual program. As for the interpretation of the set of equalities in (35)-(37), (39)-(42) and (44)-(63), it can be noticed that if two numbers $A$ and $B$ satisfy $A B=0$ and $A, B \geq 0$ then the following conclusion can be drawn: (i) if $A>0$ then $B=0$, and (ii) if $B>0$ then $A=0$.

\subsection{Data-boxes}

The primal and dual programs of the stylized interport problem can be spelled out in more detail and simultaneously seen by writing the so-called 'data-boxes'. In particular, it can be drawn one data-box for analyzing all road and rail traffic of full containers supplied at the seaport node 1 (Tab. 1) and another one for analyzing all road and rail traffic of empty containers supplied at the same node 1 (Tab.2). In addition, it can be drawn a third data-box for all rail traffic of full and empty containers supplied at the seaport (Tab. 3).

The top row of each data-box shown in Tables 1-2 lists the unknowns of the primal problem, i.e. the $x$ variables. Instead, the entries in the first column of each data-box in Tables 1-2 are unknowns of the dual problem, i.e. the $v$ variables.

The bottom row of each data-box provided in Tables 1-2 lists the unit total social logistic costs of port hinterland container distribution. Reading the top row and the bottom row together for each data-box, they form the minimand (1) of the primal programming problem.

The main body of each data-box in Tables 1-2 consists of the 'node-link incidence matrix' of the network, which completely describes the physical layout of the multimodal network. It has one column for each permitted link and one row for each node. There are exactly two non-zero entries in each column: -1 at the originating node of the link and +1 at the destination node. Totally, there are twenty one columns and six rows forming the node-link incidence matrix of the data-box for full containers, whereas there are fourteen columns and six rows forming the incidence matrix of the data-box for empty containers.

Reading the top row and the incidence matrix together in each data-box (Tabb. 1-2), they form the left-hand sides appearing in the flow conservation constraints (2)-(4) for each type of traffic (full and empty containers) in the primal program. The last column of each data-box lists the vector of container supplies and demands specified by O/D pairs, i.e. the right-hand sides appearing in flow conservation constraints. Together, the first seven rows (excluding the elements of the first column) in each data-box shown by Tables 1-2 exhibit the entire flow conservation constraint set for each type of container traffic. In this respect, there are twelve conservation of flows constraints all together, six constraints for the $x_{i j}^{f u l l \in T, m}$ variables and six for the $x_{i j}^{\text {empty } \in T, m}$ variables for all $i, j \in I$ and $m \in M$.

The representation of the interport problem by means of the data-boxes provided in Tables 1-2 does not take into consideration the capacity limits on railway links represented by disequations (5)(8) in the primal program. This is due to the fact that such constraints represent a kind of 'coupling conditions' tying the shipments of full and empty containers together. 
However, the railway capacity conditions of the interport problem and their corresponding dual prices are represented in the data-box shown in Table 3. The first column of this table lists the scc variables. Instead, the entries in the top row are unknowns of the primal program, i.e. the $x_{i j}^{t, r a i l \in M}$ variables for all $i, j \in I$ and $t \in T$.

The main body of the data-box in Table 3 consists of the 'rail service-rail link incidence matrix'. This matrix has one row for each rail service $a \in A$ and one column for each permitted rail link. There is exactly one non-zero entry in each column: +1 at the rail service whose originating node is also the originating node of the link. Totally, there are eleven columns and four rows forming the rail service-rail link incidence matrix of the stylized interport problem.

Reading the top row and the rail incidence matrix together in the data-box provided in Table 3 , they form the left-hand sides appearing in the capacity constraints (5)-(8) in the primal program. The last column of the data-box lists the right-hand sides appearing in such primal constraints. Together, the first five rows of the matrix (excluding the elements of the first column) exhibit the entire capacity constraint set of the primal program. In particular, there are two capacitated rail services from the seaport node 1 , and two capacitated rail services from the interport facility featuring the two virtual nodes 2 and 3.

The difference between the total shadow value of container effluxes and the total shadow cost of container influx in the maximand (12) of the dual problem can be read off by considering the first and last column together for each data-box shown in Tables 1-2. In addition, the total shadow value of rail capacity can be read off by considering together the the first and last column of the data-box shown in Table 3.

Dual constraints corresponding to road shipments and belonging to the set of constraints (13)-(32) can be read off by considering together the first column and each of its following columns corresponding to road links up to the next to last column, read one by one in each data-box provided in Tables 1-2. Instead, dual constraints corresponding to rail shipments (and belonging to the same set of constraints (13)-(32)) can be read off by considering together the first columns and each of its following columns corresponding to rail links up to the next to last columns, read one by one simultaneously in each data-box shown by Tables 1-2 and in the data-box shown by Table 3 .

The next to last row of each data-box shown in Tables 1-2 exhibits the signs of all dual constraints. These depend both on the signs of constraints on primal endogenous variables and on the type of optimand.

The data boxes also give a useful mnemonic for writing the primal and dual complementary slackness conditions. In particular, such conditions can be read off in the same manner of primal and dual constraints. Finally, it has to be noted that the incidence matrices of all data-boxes in Tables 1-3 contain the left-hand side coefficients of primal constraints, whereas their transposes contain the left-hand side coefficients of dual constraints. 
Table 1 Data-box for all multimodal traffic of full containers

\begin{tabular}{|c|c|c|c|c|c|c|c|}
\hline & $x_{12}^{\text {full, rail }}$ & $x_{12}^{\text {full, truck }}$ & $x_{13}^{\text {full, rail }}$ & $x_{14}^{\text {full, rail }}$ & $x_{14}^{\text {full, truck }}$ & $x_{15}^{\text {full, truck }}$ & \\
\hline$v_{1}^{\text {full }}$ & -1 & -1 & -1 & -1 & -1 & -1 & $\ldots$ \\
\hline$v_{2}^{\text {full }}$ & 1 & 1 & 0 & 0 & 0 & 0 & $\ldots$ \\
\hline$v_{3}^{\text {full }}$ & 0 & 0 & 1 & 0 & 0 & 0 & $\cdots$ \\
\hline$v_{4}^{\text {full }}$ & 0 & 0 & 0 & 1 & 1 & 0 & $\ldots$ \\
\hline$v_{5}^{\text {full }}$ & 0 & 0 & 0 & 0 & 0 & 1 & $\cdots$ \\
\hline \multirow[t]{3}{*}{$v_{6}^{\text {full }}$} & 0 & 0 & 0 & 0 & 0 & 0 & $\cdots$ \\
\hline & $\leq$ & $\leq$ & $\leq$ & $\leq$ & $\leq$ & $\leq$ & \\
\hline & $\left(c_{12}^{\text {full, rail }}+g_{1}^{\text {rail }}\right)$ & $\left(c_{12}^{\text {full, truck }}+g_{1}^{\text {truck }}\right)$ & $\left(c_{13}^{f u l l, \text { rail }}+k_{1}\right)$ & $\left(c_{14}^{f u l l, \text { rail }}+g_{1}^{\text {rail }}\right)$ & $\left(c_{14}^{\text {full, truck }}+g_{1}^{\text {truck }}\right)$ & $\left(c_{15}^{\text {full, truck }}+g_{1}^{\text {truck }}\right)$ & \\
\hline
\end{tabular}

Table 1 (continued)

\begin{tabular}{|c|c|c|c|c|c|c|c|}
\hline$\ldots$ & $x_{16}^{\text {full, truck }}$ & $x_{24}^{\text {full, rail }}$ & $x_{24}^{\text {full, truck }}$ & $x_{25}^{\text {full, rail }}$ & $x_{25}^{\text {full, truck }}$ & $x_{26}^{\text {full, truck }}$ & $\cdots$ \\
\hline$\ldots$ & -1 & 0 & 0 & 0 & 0 & 0 & .. \\
\hline$\ldots$ & 0 & -1 & -1 & -1 & -1 & -1 & \\
\hline$\cdots$ & 0 & 0 & 0 & 0 & 0 & 0 & $\ldots$ \\
\hline$\cdots$ & 0 & 1 & 1 & 0 & 0 & 0 & .. \\
\hline$\cdots$ & 0 & 0 & 0 & 1 & 1 & 0 & $\ldots$ \\
\hline$\cdots$ & 1 & 0 & 0 & 0 & 0 & 1 & $\ldots$ \\
\hline$\cdots$ & $\leq$ & $\leq$ & $\leq$ & $\leq$ & $\leq$ & $\leq$ &.. \\
\hline$\cdots$ & $\left(c_{16}^{\text {full, truck }}+g_{1}^{\text {truck }}\right)$ & $\left(c_{24}^{\text {full, rail }}+s_{2}^{\text {rail }}\right)$ & $\left(c_{24}^{\text {full, truck }}+s_{2}^{\text {truck }}\right)$ & $\left(c_{25}^{\text {full, rail }}+s_{2}^{\text {rail }}\right)$ & $\left(c_{25}^{\text {full, truck }}+s_{2}^{\text {truck }}\right)$ & $\left(c_{26}^{\text {full, truck }}+s_{2}^{\text {truck }}\right)$ & \\
\hline
\end{tabular}


Table 1 (continued)

\begin{tabular}{|c|c|c|c|c|c|c|c|}
\hline$\ldots$ & $x_{32}^{\text {full, truck }}$ & $x_{34}^{\text {full, rail }}$ & $x_{34}^{f u l l, \text { truck }}$ & $x_{35}^{\text {full, rail }}$ & $x_{35}^{\text {full, truck }}$ & $x_{36}^{f u l l, \text { truck }}$ & \\
\hline$\ldots$ & 0 & 0 & 0 & 0 & 0 & 0 & $\ldots$ \\
\hline$\ldots$ & 1 & 0 & 0 & 0 & 0 & 0 & $\ldots$ \\
\hline$\ldots$ & -1 & -1 & -1 & -1 & -1 & -1 & $\ldots$ \\
\hline$\ldots$ & 0 & 1 & 1 & 0 & 0 & 0 & $\ldots$ \\
\hline$\ldots$ & 0 & 0 & 0 & 1 & 1 & 0 & $\ldots$ \\
\hline$\ldots$ & 0 & 0 & 0 & 0 & 0 & 1 & $\ldots$ \\
\hline$\ldots$ & $\leq$ & $\leq$ & $\leq$ & $\leq$ & $\leq$ & $\leq$ & $\ldots$ \\
\hline$\cdots$ & $\left(c_{32}^{\text {full, truck }}+u_{3}^{\text {truck }}\right)$ & $\left(c_{34}^{\text {full, rail }}+u_{3}^{\text {rail }}\right)$ & $\left(c_{34}^{\text {full, truck }}+u_{3}^{\text {truck }}\right)$ & $\left(c_{35}^{\text {full, rail }}+u_{3}^{\text {rail }}\right)$ & $\left(c_{35}^{\text {full, truck }}+u_{3}^{\text {truck }}\right)$ & $\left(c_{36}^{\text {full, truck }}+u_{3}^{\text {truck }}\right)$ & $\cdots$ \\
\hline
\end{tabular}

\section{Table 1 (continued)}

\begin{tabular}{|c|c|c|c|l|}
\hline$\ldots$ & $x_{45}^{\text {full, truck }}$ & $x_{54}^{\text {full, truck }}$ & $x_{56}^{\text {full, truck }}$ & \\
\hline$\ldots$ & 0 & 0 & 0 & $\geq-$ Demand $_{11}^{\text {full }}$ \\
\hline$\ldots$ & 0 & 0 & 0 & $\geq$ Demand $_{12}^{\text {full }}$ \\
\hline$\ldots$ & 0 & 0 & 0 & $\geq$ Demand $_{13}^{\text {full }}$ \\
\hline$\ldots$ & -1 & 1 & 0 & $\geq$ Demand $_{14}^{\text {full }}$ \\
\hline$\ldots$ & 1 & -1 & -1 & $\geq$ Demand $_{15}^{\text {full }}$ \\
\hline$\ldots$ & 0 & 0 & 1 & $\geq$ Demand $_{16}^{\text {full }}$ \\
\hline$\ldots$ & $\leq$ & $\leq$ & $\leq$ & \\
\hline$\ldots$ & $\left(c_{45}^{\text {full, truck }}\right)$ & $\left(c_{54}^{\text {full, truck }}\right)$ & $\left(c_{56}^{\text {full, truck }}\right)$ & \\
\hline
\end{tabular}


Table 2 Data-box for all multimodal traffic of empty containers

\begin{tabular}{|c|c|c|c|c|c|c|c|}
\hline & $x_{12}^{\text {empty, rail }}$ & $x_{12}^{\text {empty, truck }}$ & $x_{14}^{\text {empty, rail }}$ & $x_{14}^{\text {empty, truck }}$ & $x_{15}^{\text {empty, truck }}$ & $x_{16}^{\text {empty, truck }}$ & $\cdots$ \\
\hline$v_{1}^{\text {empty }}$ & -1 & -1 & -1 & -1 & -1 & -1 & $\ldots$ \\
\hline$v_{2}^{\text {empty }}$ & 1 & 1 & 1 & 1 & 0 & 0 & $\ldots$ \\
\hline$v_{3}^{\text {empty }}$ & 0 & 0 & 0 & 0 & 0 & 0 & $\ldots$ \\
\hline$v_{4}^{\text {empty }}$ & 0 & 0 & 0 & 0 & 0 & 0 & $\ldots$ \\
\hline$v_{5}^{\text {empty }}$ & 0 & 0 & 0 & 0 & 1 & 0 & $\cdots$ \\
\hline \multirow[t]{3}{*}{$v_{6}^{\text {empty }}$} & 0 & 0 & 0 & 0 & 0 & 1 & $\ldots$ \\
\hline & $\leq$ & $\leq$ & $\leq$ & $\leq$ & $\leq$ & $\leq$ & $\ldots$ \\
\hline & $\left(c_{12}^{\text {empty, rail }}+f_{1}\right)$ & $\left(c_{12}^{\text {empty, truck }}+f_{1}\right)$ & $\left(c_{14}^{\text {empty, rail }}+f_{1}\right)$ & $\left(c_{14}^{\text {empty, truck }}+f_{1}\right)$ & $\left(c_{15}^{\text {empty, truck }}+f_{1}\right)$ & $\left(c_{16}^{\text {empty, truck }}+f_{1}\right)$ & $\ldots$ \\
\hline
\end{tabular}

Table 2 (continued)

\begin{tabular}{|c|c|c|c|c|c|c|c|}
\hline$\ldots$ & $x_{24}^{\text {empty, rail }}$ & $x_{24}^{\text {empty, truck }}$ & $x_{25}^{\text {empty, rail }}$ & $x_{25}^{\text {empty, truck }}$ & $x_{26}^{\text {empty, truck }}$ & $x_{45}^{\text {empty, truck }}$ & $\ldots$ \\
\hline$\ldots$ & 0 & 0 & 0 & 0 & 0 & 0 & $\ldots$ \\
\hline$\ldots$ & -1 & -1 & -1 & -1 & -1 & 0 & $\ldots$ \\
\hline$\ldots$ & 0 & 0 & 0 & 0 & 0 & 0 & $\ldots$ \\
\hline$\ldots$ & 1 & 1 & 0 & 0 & 0 & -1 & $\ldots$ \\
\hline$\ldots$ & 0 & 0 & 1 & 1 & 0 & 1 & $\ldots$ \\
\hline$\ldots$ & 0 & 0 & 0 & 0 & 1 & 0 & $\ldots$ \\
\hline$\ldots$ & $\leq$ & $\leq$ & $\leq$ & $\leq$ & $\leq$ & $\leq$ & $\ldots$ \\
\hline$\ldots$ & $\left(c_{24}^{\text {empty, rail }}+f_{2}\right)$ & $\left(c_{24}^{\text {empty, truck }}+f_{2}\right)$ & $\left(c_{25}^{\text {empty, rail }}+f_{2}\right)$ & $\left(c_{25}^{\text {empty, truck }}+f_{2}\right)$ & $\left(c_{26}^{\text {empty, truck }}+f_{2}\right)$ & $\left(c_{45}^{\text {empty, truck }}\right)$ & $\ldots$ \\
\hline
\end{tabular}


Table 2 (continued)

\begin{tabular}{|c|c|c|l|}
\hline$\ldots$ & $x_{54}^{\text {empty, truck }}$ & $x_{56}^{\text {empty, truck }}$ & \\
\hline$\cdots$ & 0 & 0 & $\geq-$ Demand $_{11}^{\text {empty }}$ \\
\hline$\cdots$ & 0 & 0 & $\geq$ Demand $_{12}^{\text {empty }}$ \\
\hline$\cdots$ & 0 & 0 & $\geq$ Demand $_{13}^{\text {empty }}$ \\
\hline$\cdots$ & 1 & 0 & $\geq$ Demand $_{14}^{\text {empty }}$ \\
\hline$\cdots$ & -1 & -1 & $\geq$ Demand $_{15}^{\text {empty }}$ \\
\hline$\cdots$ & 0 & 1 & $\geq$ Demand $_{16}^{\text {empty }}$ \\
\hline$\cdots$ & $\leq$ & $\leq$ & \\
\hline$\cdots$ & $\left(c_{54}^{\text {empty, truck }}\right)$ & $\left(c_{56}^{\text {empty, truck }}\right)$ & \\
\hline
\end{tabular}

Table 3 Data-box for all rail traffic of full and empty containers

\begin{tabular}{|c|c|c|c|c|c|c|c|}
\hline & $x_{12}^{\text {full, rail }}$ & $x_{12}^{\text {empty, rail }}$ & $x_{13}^{\text {full, rail }}$ & $x_{14}^{\text {full, rail }}$ & $x_{14}^{\text {empty, rail }}$ & $x_{24}^{\text {full, rail }}$ & $\ldots$ \\
\hline$s c c_{1 \_(2+3)}$ & 1 & 1 & 1 & 0 & 0 & 0 & $\cdots$ \\
\hline$s c c_{1 \_4}$ & 0 & 0 & 0 & 1 & 1 & 0 & $\cdots$ \\
\hline$s c c_{(2+3) \_}$ & 0 & 0 & 0 & 0 & 0 & 1 & $\cdots$ \\
\hline$s c c_{(2+3) \_5}$ & 0 & 0 & 0 & 0 & 0 & 0 & $\cdots$ \\
\hline
\end{tabular}


Table 3 (continued)

\begin{tabular}{|c|c|c|c|c|c|c|}
\hline$\ldots$ & $x_{24}^{\text {empty, rail }}$ & $x_{25}^{\text {full, rail }}$ & $x_{25}^{\text {empty, rail }}$ & $x_{34}^{\text {full, rail }}$ & $x_{35}^{\text {full, rail }}$ & \\
\hline$\cdots$ & 0 & 0 & 0 & 0 & 0 & $\leq b_{1 \_(2+3)}$ \\
\hline$\cdots$ & 0 & 0 & 0 & 0 & 0 & $\leq b_{1 \_4}$ \\
\hline$\cdots$ & 1 & 0 & 0 & 1 & 0 & $\leq b_{(2+3) \_4}$ \\
\hline$\cdots$ & 0 & 1 & 1 & 0 & 1 & $\leq b_{(2+3) \_5}$ \\
\hline
\end{tabular}




\section{Conclusions}

Optimization of port hinterland container logistics is crucial to meet rising international trade demand and the challenges related to sustainable development. Inefficient hinterland connections undermine the competitiveness both of seaports and of the wider regional logistics and productive systems the seaports belong to.

The extended gateway concept is gaining more and more momentum as a business network innovation based on the possibility of duplicating and/or complementing some container seaport activities at hinterland intermodal facilities called dry ports (or interports). If properly implemented in port hinterland network systems, extended gateways can relieve seaport congestion phenomena, promote the shift of standardized loading units from road-only transport to sustainable inland transport solutions, and stimulate integrated freight logistics operations inland, thus reducing the internal and external costs of supply chains and promoting regional economic growth.

This paper has illustrated the interport model as a mathematical programming tool for the economic analysis and strategic planning of such kind of innovation. The primal and dual formulations and interpretations of a stylized version of the model optimizing the distribution of import containers through a hypothetical integrated regional seaport-interport network system under a sustainable logistics perspective have been provided, including complementary slackness relations and the model representation by means of data-boxes.

Shipping lines and freight forwarders could employ the model for evaluating criticalities and opportunities related to their port hinterland distribution systems. Seaports, interports, intermodal marketing companies and inland carriers could evaluate the system-wide effects of economic and logistic type deriving from their decisions and/or from the decisions of their competitors. Government agencies could evaluate the infrastructural and territorial impacts related to variations in traffic flows, as well as the impacts on traffic flows due to infrastructure investment decisions, new regulations, and policies providing financial grants to improve services. In this latter case, the model could be empirically applied to assess public policy measures providing for incentives to intermodal transport services based on the total external cost saving deriving from shifting containers from road only transport. By this way it will be possible to support the implementation of well suit pricing systems taking care of a better spread of traffic and a more fair division between different modes of transport, and to resolve, at least in part, a number of bottlenecks in the hinterland connections of some seaports.

The interport model can be a useful tool to evaluate possible changes in hinterland contestability arising from different policy scenarios concerning the sea-land intermodal logistics system of multiple regions in a country, as well as that of an entire country or even a group of countries. An example could be the so called "ARA region" (Amsterdam-Rotterdam-Antwerp) in Northern Europe. A successful real case of extended gateway logistics in Europe is represented by the system of terminals and services arranged by Europe Container Terminals (ECT) to serve the hinterland traffic of containers transiting through the port of Rotterdam, in the Netherlands. At the moment, ECT operates three deep-sea terminals in Rotterdam plus various hinterland terminals at strategic locations throughout the Netherlands, Belgium and Germany, covering substantial parts of Western Europe and introducing important innovations in port hinterland container distribution such as the terminal operator haulage concept, and the cross-border extended gateway concept at a transEuropean level.

As for possible empirical applications of the model to investigate port hinterland container logistics issues in Italy, these could concern the evaluation of public and private initiatives aimed at integrating the operations of different actors, as already demonstrated by Iannone and Thore (2010) with regards to inland container operations at the Campanian regional logistics system. On the other hand, container seaports and inland freight centres are nowadays part of territorial logistics systems and complex supply chains, and there is competition between integrated networks rather than between single hubs and between single operators. Indeed, the practical implementation of the extended gateway concept within a territorial logistics system requires cooperation and integration 
among a number of players, including seaports, interports, shipping lines, inland intermodal carriers, customs, and so on.

In Italy, there are not examples of shipping lines investing in interports, and also maritime terminal companies and freight forwarders are still reluctant to engage clear long term partnership with interports in the fear of core activities shift to other operators. Only 14 interports have an onsite customs office, and in some cases the intermodal terminal operating companies have not yet been authorized at operating a so-called 'A3 area', that is a bonded zone for the handling and storage of international containerized cargoes that need to be examined and cleared by customs. In addition, by virtue of an ancient customs regime still in force, the port-interport rail connections can be employed only for merchant traffics if operated by private rail traction providers. Port-interport container forwarding solutions arranged by shipping lines according to the extended gateway concept (i.e. without the need for customs transit documentation) are possible only where rail services provided by the Italian State-owned rail carrier are available (for instance between the seaport of Genoa in Liguria region and the interport of Rivalta Scrivia in Piedmont region).

'Trenitalia' is the incumbent rail traction provider belonging to the State-owned rail holding FS Group ('Gruppo Ferrovie dello Stato') and the only rail company authorized to operate services under facilitated conditions for customs bonded containers travelling under steamship bills of lading from and to the Italian seaports. At the moment, Trenitalia has ceased to operate container rail services between some Italian seaports and interports (such as for instance in the Campania region) mainly due to severe financial problems that are bringing to a reorganization of the cargo division of the company. Possible future successful implementations of extended gateway systems in Italy should therefore also imply greater liberalization and further regulatory changes for rail traction service provision in port hinterland container markets.

As for some limitations of the current formulation of the interport model, a major abstraction in linear programming is that the objective function and the constraints are formulated by summing individual terms that are proportional to the values of variables. There are many real-word problems, however, in which non linearities are present. For instance, there might be economies of scale that allow one to reduce costs as volume of activities increases. Piecewise linear functions can therefore be used to represent economies of scale in logistic costs associated with concentrated flows.

Furthermore, the deterministic assumption in the interport model has been designed to keep the analysis at a basic level, recognizing that most real problems contains deterministic elements as well as random parameters with accompanying probability distributions. For instance, terminal and customs operations and delays could be modelled by using queuing theory, dynamic programming and stochastic programming.

A specific aspect that would deserve attention is the modelling of reliability, including safety stocks and their associated costs. Shippers or consignees may not be interested in fast deliveries, and yet a delay with respect to an expected delivery time may produce a great damage, sometimes even a far greater damage than what should have been borne to obtain a timely delivery by using a more expensive transport solution. When investigating such cases, the valuation fundamentally depends on the value of goods and the needs of the consignees. In this respect, it is not an easy task obtaining detailed data on stated or revealed preferences of the consignees.

As from business logistics literature, buffer inventories can be calculated based essentially on: i) the customer service level, ii) the uncertainty in shipment lead time, and iii) the demand forecast error. Hence, the transit time of transport services is only a part of the total lead time of shipments. The main challenge in port hinterland container logistics modelling seems to be that of calculating the unit safety stock costs at destination in relation to the movements of full containers transported simultaneously by different and alternative transport solutions featuring different lead times. In the currently available literature on container network optimization, safety stock costs are calculated only relating to the deliveries of total batches of containers by single transport solutions (Jula and Leachman, 2011; Leachman, 2008); this means that each destination is supposed to be served by a 
single transport solution only. In our opinion, a good starting point for more realistic approximations of safety inventories are the analytical results achieved by Boute and Van Mieghem (2011) and Combes (2011). These contributions show how to estimate the safety stock for a single good that is sourced from two locations ("dual sourcing") or by using simultaneously different transport solutions.

Finally, negative environmental and social impacts of distribution operations (e.g. atmospheric emissions) are currently entered into the model only in monetary terms, but they can be formulated and taken into account also in physical terms. Multi-objective modelling techniques are particularly suitable for decision problems involving trade-offs among conflicting goals such as the simultaneous minimization of internal logistics costs and physical environmental impacts of porthinterland container distribution. Multiple non-dominated or "Pareto-optimal" solutions of the model can be obtained by applying the augmented $\mathcal{E}$-constraint method (AUGMECON), first introduced by Mavrotas (2009).

\section{References}

Aponte, D., Iannone, F. and Papola, A. (2009), 'A Schedule-based Methodology Proposal for Sea Motorways Feasibility Evaluation', In N.H.M.Wilson and A. Nuzzolo (eds), Schedule-Based Modelling of Transportation Networks. Theory and Applications, Operations Research/Computer Science Interfaces Series, 46, New York: Springer, 251-266.

Bontekoning, Y.M., Macharis, C and Trip J.J. (2004), 'Is a new applied transportation research field emerging? A review of intermodal rail-truck freight transport literature', Transportation Research Part A, 38 (1), 1-34.

Boute, R.N. and Van Mieghem, J.A. (2011), 'Global Dual Sourcing and Order Smoothing', mimeo, available at http://www.kellogg.northwestern.edu/faculty/vanmieghem/articles.htm.

Caris, A., Macharis, C. and Janssens, G.K. (2008), 'Planning Problems in Intermodal Freight Transport: Accomplishments and Prospects', Transportation Planning and Technology, 31 (3), 277-302.

Combes, F. (2011), 'Inventory theory and mode choice in freight transport: the case of the simultaneous use of two transport modes on one shipper-receiver relationship', European Transport Conference 2011 Proceedings, 10-12 October, Glasgow, Scotland, UK.

Crainic, T.G. and Kim, K.H. (2007), 'Intermodal Transportation', In C. Barnhart and G. Laporte (eds), Transportation, Handbooks in Operations Research and Management Science, NorthHolland, Amsterdam, 467-537.

Cullinane, K. and Wilmsmeier, G. (2011), "The contribution of the dry port concept to the extension of port life cycles”, In: J.W. Böse (ed), Handbook of Terminal Planning, New York: Springer, 359-379.

Danielis, R. (2006), 'Il Trasporto Intermodale Ferroviario: Quale Ruolo per l'Analisi Economica?', In G. Polidori, E. Musso and E. Marcucci (eds), I Trasporti e l'Europa. Politiche, Infrastrutture e Concorrenza, FrancoAngeli, Milan, 159-171.

Harrison, R. (2007), 'International Trade, Transportation Corridors, and Inland Ports: Opportunities for Canada', paper presented at the Canada's Asia-Pacific Gateway and Corridor Initiative International Conference, CTS - Center for Transportation Studies, University of British Columbia, Vancouver, May.

Hayut, Y. (1980), 'Inland container terminal - function and rationale', Maritime Policy \& Management, 7 (4), 283-289.

Iannone, F. and Thore, S. (2010) 'An economic logistics model for the multimodal inland distribution of maritime containers', International Journal of Transport Economics, 37 (3), 281326.

Iannone, F., Thore, S. and Forte, E. (2007), 'Inland Container Logistics and Interports. Goals and Features of an Ongoing Applied Research', In G. Borruso, E. Forte and E. Musso (2009) (eds), 
Economia dei Trasporti e Logistica Economica:Ricerca per l'Innovazione e Politiche di Governance, Naples: Giordano Editore, 385-414.

Jaržemskis, A. and Vasiliauskas, A.V. (2007), 'Research on dry port concept as intermodal node', Transport, 22 (3), 207-213.

Jensen, P.A. and Bard, J.F. (2003), Operations Research: Models and Methods, New York: John Wiley \& Sons.

Jula, P., Leachman, R.C. (2011), 'A supply-chain optimization model of the allocation of containerized imports from Asia to the United States', Transportation Research Part E, 47 (5), 609-622.

Kirkland, C. (2007), 'Assessing Potential for Inland Port Success', paper presented at the Canada's Asia-Pacific Gateway and Corridor Initiative - International Conference, CTS - Center for Transportation Studies, University of British Columbia, Vancouver, Canada, May.

Leachman, R. (2008), 'Port and modal allocation of waterborne containerized imports from Asia to the United States',Transportation Research E, 44 (2), 313-331.

Leitner, S. J. and Harrison, R. (2001), 'The identification and classification of inland ports', Research Report Number 0-4083-1, Center for Transportation Research, Bureau of Engineering Research, The University of Texas at Austin.

Leveque, P. and Roso, V. (2002), 'Dry Port Concept for Seaport Inland Access with Intermodal Solutions', Masters Thesis, Department of Logistics and Transportation, Chalmers University of Technology.

Macharis, C. and Bontekoning, Y.M. (2004), 'Opportunities for OR in intermodal freight transport research: a Review', European Journal of Operational Research, 153 (2), 400-416.

Mavrotas, G. (2009), 'Effective implementation of the $\varepsilon$-constraint method in Multi-Objective Mathematical Programming problems', Applied Mathematics and Computation, 213 (2), 455465.

Rodrigue, J.-P., Debrie, J., Fremont, A. and Gouvernal, E. (2010), 'Functions and Actors of Inland Ports: European and North American Dynamics', Journal of Transport Geography, 18 (4), 519529.

Rodrigue, J.-P. and Notteboom, T. (2009), 'The Terminalization of Supply Chains: Reassessing the Role of Terminals in Port / Hinterland Logistical Relationships', Maritime Policy \& Management, 36 (2), 165-183.

Roso, V. (2008), 'Factors influencing implementation of a dry port', International Journal of Physical Distribution \& Logistics Management, 38 (10), 782-798.

Roso, V. and Lumsden, K. (2010), 'A review of dry ports', in Maritime Economics \& Logistics, 12 (2), 196-213.

Schwarz F. (2008), 'Intermodal freight network modelling', In R. Konings, H. Priemus and P. Nijkamp (eds), The Future of Intermodal Freight Transport. Operations, Design and Policy, Edward Elgar, Cheltenham, UK, and Northampton, MA, USA, 206-222.

Thompson, G.L. and Thore, S. (1992) Computational Economics: Economic Modelling with Optimization Software. San Francisco: The Scientific Press.

Thore, S. (2007), 'Some Thoughts on the Past and the Future of Economic Logistics', In G. Borruso, E. Forte E. and E. Musso (2009) (eds), Economia dei Trasporti e Logistica Economica: Ricerca per l'Innovazione e Politiche di Governance, Naples: Giordano Editore, 24-26.

Thore, S. and Iannone, F. (2005), 'The hub-and-spoke model. A tutorial', mimeo, Carvoeiro,

Portugal, August, available at http://www.stenthore.info/computational.htm.

UNCTAD (1982), Multimodal Transport and Containerisation (TD/B/C.4/238/Supplement 1, Part Five: Ports and Container Depots), Geneva.

UNCTAD (1991), Handbook on the Management and Operation of Dry Ports, United Nations, Geneva. 
Veenstra, A. and Zuidwijk, R. (2010), 'The future of seaport hinterland networks', In L. Kroon, R. Zuidwijk and T. Li (eds), Liber Amicorum Jo van Nunen, Dinalog and RSM-Erasmus University of Rotterdam, 205-215. 